\title{
The Effect of Chromosome Structure upon Meiotic Homologous and Homoeologous Recombinations in Triticeae
}

\author{
Tomás Naranjo $\mathbb{D}$ \\ Departamento de Genética, Fisiología y Microbiología, Facultad de Biología, Universidad Complutense de \\ Madrid, 28040 Madrid, Spain; toranjo@bio.ucm.es; Tel.: +34-913945040
}

Received: 23 August 2019; Accepted: 11 September 2019; Published: 14 September 2019

\begin{abstract}
The tribe Triticeae contains about 500 diploid and polyploid taxa, among which are important crops, such as wheat, barley and rye. The phylogenetic relationships, genome compo-sition and chromosomal architecture, were already reported in the pioneer genetic studies on these species, given their implications in breeding-related programs. Hexaploid wheat, driven by its high capacity to develop cytogenetic stocks, has always been at the forefront of these studies. Cytogenetic stocks have been widely used in the identification of homoeologous relationships between the chromosomes of wheat and related species, which has provided valuable information on genome evolution with implications in the transfer of useful agronomical traits into crops. Meiotic recombination is non-randomly distributed in the Triticeae species, and crossovers are formed in the distal half of the chromosomes. Also of interest for crops improvement is the possibility of being able to modulate the intraspecific and interspecific recombination landscape to increase its frequency in crossover-poor regions. Structural changes may help in this task. In fact, chromosome truncation increases the recombination frequency in the adjacent intercalary region. However, structural changes also have a negative effect upon recombination. Gross chromosome rearrangements produced in the evolution usually suppress meiotic recombination between non-syntenic homoeologs. Thus, the chromosome structural organization of related genomes is of great interest in designing strategies of the introgression of useful genes into crops.
\end{abstract}

Keywords: chromosome rearrangements; meiotic recombination; crossover distribution; Triticeae; wheat; barley; rye

\section{Introduction}

The tribe Triticeae Dumort belongs to the subfamily Pooideae of the grass family Poaceae (Gramineae). About 500 taxa are included in this tribe. The number and designation of genera, species and subspecies depend upon the taxonomic criterion [1,2]. All species are considered to have a monophyletic origin, that is, they have a common ancestor, which is theoretically estimated to diverge from the other Poaceae 25 million years ago (MYA) [3,4]. Among the about 360 species in the tribe, 80 are diploids, the majority are allopolyploids derived from interspecific or intergeneric hybrids, most likely with progenitor species repeatedly involved in different hybridization events and increasing polyploidy levels. Only a few species are considered autopolyploids, which originated mainly from intraspecific hybridization followed by chromosome doubling [5]. All species have a basic haploid chromosome number of $x=7$; diploid species have $2 n=14$ chromosomes, and polyploids possess multiples of 14 chromosomes, the tetraploids $2 n=4 x=28$, and the hexaploids $2 n=6 x=42$. Elymus shows the most complex series and the highest level $(12 x)$ of ploidy [2]. 
Some species are self-pollinated, and others are cross-pollinated. About $75 \%$ of Triticeae species are perennials that grow in Temperate and Artic regions, mainly in the Northern Hemisphere, while the annuals spread through the Eastern Mediterranean and Central Asiatic regions [2].

The tribe is the subject of many research areas such as archaeology, genetics, plant breeding and evolutionary biology, but the main interest is due to its global economic significance, as it includes grain crops such as wheat (Triticum), barley (Hordeum) and rye (Secale), as well as a considerable number of grasses used for animal feed or rangeland protection. Given the enormous capacity for interspecific hybridization among most of the Triticeae taxa, wild species represent an accessible source of genetic variability that can be used to improve crops. The taxonomy of the tribe is complex, and has varied over time according to the taxonomic criteria and methodologies used [1]. Probably, interspecific hybridization and a large number of allopolyploid species are the key factors in the appearance of inconsistencies between different phylogenetic trees. However, the role of the wild species as potential donors of useful agronomic traits to be introgressed into their cultivated relatives, represents an additional incentive in resolving the supposed evolutionary relationships among them.

With regards to the divergence of different genera there is a common consent that Psathyrostachys and Hordeum diverged early on from the rest of the Triticeae. Aegilops and Triticum are closely related genera with a more recent origin. The estimates of the divergent times suggest that Hordeum diverged 11 MYA, Secale 7 MYA and the Aegilops-Triticum complex 2.5-4.5 MYA [4]. Hordeum originated in western Eurasia, and later extended over The Northern Hemisphere, South Africa and South America. It contains about 33 species. Four genomes have been described $\mathrm{H}, \mathrm{I}, \mathrm{Xa}$ and $\mathrm{Xu}$, which are present in diploid (2x), tetraploid ( $4 x)$ and hexaploid (6x) taxa [6]. The $\mathrm{H}$ genome is present in barley, H. vulgare, and H. bulbosum, $\mathrm{Xu}$ in H. murinum, Xa in H. marinum, and the remaining species share variants of the I genome. Barley, used to feed livestock, and malted for beer or whisky (also whiskey) production, is the economically most important species in the genus, with a world production of about 147.40 million metric tons in 2017 (http://www.fao.org/faostat/es/\#data/QC). It ranks the fourth in both quantity produced and in area of cultivation of cereal crops in the world. The barley genome has a size of $5.1 \mathrm{~Gb}$, and contains 30,400 genes [7]. Its chromosomes are designated $1 \mathrm{H}$ to $7 \mathrm{H}$ according to the homoeologous relationships relative to the wheat chromosomes. The taxonomy of the genus Secale has been a matter of disagreement. The about 15 species initially recognized were reduced to three, $S$. strictum, S. sylvestre and S. cereale. This S. strictum, the perennial species of the genus, is considered the ancestral taxon. The other two species are annual, and S. sylvestre diverged first from S. strictum, while $S$. cereale is the youngest species of the group, and includes also $S$. vavilovi [8]. Rye (S. cereale) is the sixth most important cereal in production with a total of 13.73 million metric tons in 2017 (http://www.fao.org/faostat/es/\#data/QC). Rye also has a large genome $(8.1 \mathrm{~Gb}$, nearly $50 \%$ larger than the barley genome) with 31,000 detected genes [9]. Chromosomes of rye are designated $1 \mathrm{R}$ to $7 \mathrm{R}$, according to the homoeologous relationships relative to wheat chromosomes.

The wheat-Aegilops complex consists of three genera, Amblyopirum, Aegilops and Triticum, with one, 10 and two diploid species each, respectively. Based on the genome divergence, these diploid species were classified in seven groups: T-group (A. muticum); S-group (Ae. speltoides, Ae. bicornis, Ae. longissima, Ae. sharonensis, and Ae. searsii); A-group (T. monococcum and T. urartu); D-group (Ae. tauschii); C-group (Ae. caudata); M-group (Ae. comosa and Ae. uniaristata); U-group (Ae. umbellulata) [2]. In addition to the diploids, the Aegilops genus contains 10 allotetraploid species: Ae. biuncialis (UUMM), Ae. geniculata (MMUU), Ae. neglecta (UUMM), Ae. columnaris (UUMM), Ae triuncialis (UUCC), Ae. kotschyi (SSUU), Ae. peregrina (SSUU), Ae. cylindrica (CCDD), Ae. crassa (DDMM), and Ae. ventricosa (DDNN), and four allohexaploids: Ae. recta (UUMMNN), Ae. vavilovi (DDMMSS), Ae. crassa (DDDDMM), and Ae. juvenalis (DDMMUU).

The genus Triticum contains two tetraploid species, T. turgidum (AABB) and T. timopheevii (AAGG), the allohexaploid T. aestivum (AABBDD) and the autoallohexaploid T. zhukovskyi (AAGGA ${ }^{\mathrm{m}} \mathrm{A}^{\mathrm{m}}$ ). T. turgidum and T. aestivum constitute the Emmer lineage, and T. timopheevii and T. zhukovskyi constitute the Timopheevii lineage of polyploid wheats. Triticum is the most important genus of the tribe Triticeae 
for its agricultural value. Its ranks the second after corn in grain production, contributing about $20 \%$ of the total calories consumed by humans.

The world production of wheat reached 771.72 million metric tons in 2017 (http://www.fao.org/ faostat/es/\#data/QC), most of which is bread wheat, T. aestivum. Several studies on the divergence time of the diploid genomes of the wheat-Aegilops complex agree in showing the A and S genomes as the basal branches of the group, while the D genome diverged later [10-12]. Feldman and Levy [2] suggested a reticulate evolution in the group, in which the primitive diploid species diverged theoretically 2.5-3.0 MYA, and the more recent ones 2.5 MYA. The three ploidy levels of the wheat group contain cultivated species. One diploid species, T. monococcum, and the two tetraploids, were domesticated with the birth of agriculture about 10,000 years ago, while T. aestivum and T. zhukovskyi are considered to be originated under the cultivation of T. turgidum and T. timopheevii, respectively. Wild tetraploid wheat, $T$. turgidum ssp. dicoccoides (AABB) is believed to have originated within the past few hundred thousand years [4] from the hybridization of wild diploid einkorn wheat, T. urartu (AA), with a close relative of Ae. speltoides (SS, where $\mathrm{S}$ is closely related to B) [13-15]. The hexaploid T. aestivum (AABBDD) originated from a second hybridization event between T. turgidum and the wild diploid progenitor of the D genome, Ae. tauschii $[16,17]$. T. timopheevii originated 0.4 MYA [4,12], its A-genome was derived from T. urartu [13], while the G-genome originated from the S-genome of Ae. speltoides [15,18-23]. The hexaploid wheat T. zhukovskyi originated from the hybridization of T. timopheevii and T. monococcum $[13,24]$. Bread wheat has a large genome $(17 \mathrm{~Gb})$, whose reference sequence has been identified with an estimated coverage of $94 \%$, giving access to 107,891 high-confidence genes [25,26]. A 10.5-Gb genome assembly composed of 14 pseudomolecule sequences representing the 14 chromosomes of wild emmer wheat (genome size estimated to be $12 \mathrm{~Gb}$ ) was also reported [27]. Other wheat-relative genome sequences, including those of T. urartu $(4.94 \mathrm{~Gb})$ and Ae. tauschii (4.5 Gb), have been published [28,29].

Many studies carried out in order to identify the diploid progenitors of the allopolyploid species in the wheat-Aegilops complex were based in the genome analysis developed by Kihara [30-33]. This method assumed that the genetic architecture of the different genomes present in a given allopolyploid is preserved as in their diploid progenitors, making possible their identification through the analysis of meiotic pairing in interspecific crosses. A high frequency of bivalent pairing at metaphase I between the chromosomes of the diploid and polyploid species identified the homology of such genomes. Meiotic pairing also has implications on the possibility of transferring genes of agronomic interest from wild species to cultivated ones, especially to common wheat. Homologous recombination can be used in the transfer of genes from species of the primary and secondary gene pool, which share homologous genomes with common wheat. After direct hybridization and homologous recombination, useful genes can be selected in the offspring of the hybrids and in subsequent backcrosses [34]. In the case of species belonging to the tertiary gene pool, genomes are more differentiated relative to those of wheat, and any gene transfer to be achieved needs the occurrence of a recombination between homoeologous chromosomes. This became effective after the discovery of the $P h 1$ gene that suppresses recombination between homoeologous chromosomes in wheat [35-39]. In the absence of Ph1, recombination is possible between the homoeologous chromosomes of wheat or between those of wheat and other species. Alternatively, $\mathrm{Ph}$ suppressors present in Ae. speltoides can be used to induce homoeologous recombination. Different genes have been transferred from the Aegilops species via such homoeologous recombination [40]. On the other hand, meiotic recombination appears also to be the foci of current research projects because of the importance of extending their occurrence to all genomic regions, especially to those that are usually restricted. In this review, I will summarize all of the features of meiotic recombination with implications on breeding-related programs, especially those concerning polyploid wheats. 


\section{Chromosome Structure in Triticeae}

All species of the tribe Triticeae are assumed to have evolved from a common ancestor. In the species divergence, chromosomes could adopt different evolutionary paths, which can be established after unraveling the content and order of the genes present in the homoeologous linkage groups. In this task, bread wheat has played a central role.

Hexaploid wheat, T. aestivum, is the first allopolyploid in which all 21 chromosomes were identified according to its genomes of origin (A, B or D) and homoeologous groups. Such a chromosome classification was later used as a reference in the identification of the homoeologous relationships of chromosomes from other genomes of the tribe. Aneuploid sets of monosomics, nullisomis, telocentrics, trisomics and tetrasomics, as well as the 42 nullisomic-tetrasomic combinations obtained by Sears in cv. Chinese Spring [41,42], were indispensable materials used for this purpose. Unpaired chromosomes in the crosses of 21 monosomics of bread wheat and tetraploid wheat AABB were allocated to the D genome [41]. Chromosomes of the A and B genomes were identified in crosses between 13 ditelocentric lines and a synthetic tetraploid AADD [43]. Six telocentrics that formed a heteromorphic bivalent with a normal chromosome in the AABDD hybrids were assigned to the A genome, and the seven telocentrics that appeared as univalents were assigned to the B genome. The remaining chromosome, which belonged to group 4 [41], was determined to be 4A. Further studies demonstrated the initial misclassification of the chromosomes $4 \mathrm{~A}$ and $4 \mathrm{~B}$, and they were reassigned as $4 \mathrm{~B}$ and $4 \mathrm{~A}$, respectively [44].

Its hexaploid constitution confers upon bread wheat the ability of tolerating the loss of complete chromosomes, as well as the addition of chromosomes from related species without drastically affecting the viability of the plant. This ability and the crossability of wheat with different species of genera Aegilops, Haynaldia, Secale, Thinopyrum, Elymus, Leymus, Elytrigia, Roegneria or Hordeum have permitted to develop wheat-alien addition and substitution lines. Sets of wheat-alien additions are derived from backcrosses of interspecific hybrids, or synthetic allopolyploids, with wheat. Such lines contain one chromosome (monosomic addition) or one chromosome pair (disomic addition) from a given specie added to the entire chromosome complement of common wheat. Additions from more than 20 related species have been reported in bread wheat [45]. Once a complete set of wheat-alien additions is obtained, the added chromosomes are assigned to homoeologous groups based on their genetic affinity to wheat chromosomes. In wheat-alien substitution lines a pair of alien homologues are substituted for a pair of wheat chromosomes. These lines are usually more stable than addition lines, but their production requires the use of wheat-alien additions. The standard method to obtain alien substitutions is to cross a disomic addition with a wheat monosomic of the same homoeologous group of the alien chromosome, and to select the disomic substitution in the offspring of the double monosomic obtained in the cross. In the case where the homoeologous relationships of the addition lines were not established, it is possible to cross a wheat-alien addition with seven monosomics. Among the substitutions obtained, only one involving homoeologous chromosomes will produce genetic compensating and fertile plants, thus identifying the homoeologous group of the alien chromosome. The ability of an alien chromosome to compensate for the absence of a wheat chromosome resembles the nullisomic-tetrasomic compensation test used by Sears [42] in the identification of the homoeologous chromosomes of wheat, and is the most efficient method of identifying the homoeology of alien chromosomes to wheat. Telocentrics produced through a mis-division of the added chromosomes have also been recovered, and these increase the richness of cytogenetic stocks available in wheat.

Once the homoeologous relationships of chromosomes from different genomes are identified, the level of synteny that they share can be assessed using different comparative analysis. Meiotic pairing [46], physical location of low copy DNA probes [47], genetic maps [48,49] and genome sequencing [50] are different approaches used to study whether collinearity of homoeologous chromosomes is preserved or broken down by rearrangements produced during genome differentiation. 


\subsection{Durum and Bread Wheats}

Meiotic pairings have been used to study the chromosome structure of bread wheat genomes [46]. The wheat chromosome arms that paired at metaphase I in wheat $\times$ rye hybrids lacking either the $P h 1$ or Ph 2 were identified by C-banding. In most cases associations occurred between homoeologous arms, but some associations were produced between chromosome arms of different homoeologous groups.

The 4AL arm was paired with 7AS and 7DS, 5AL with 4BL and 4DL, and 7BS with 5BL and 5DL. In addition, infrequent associations of 4AL-4DS, 4AS-4BL and 4AS-4DL were also observed. Such results indicated normal homoeology for all wheat chromosome arms except 4AS, 4AL, 5AL and 7BS. The arms $4 \mathrm{AL}, 5 \mathrm{AL}$ and $7 \mathrm{BS}$ are involved in a cyclic translocation and chromosome $4 \mathrm{~A}$ in a pericentric inversion produced in the evolution of wheat. Meiotic pairing between chromosomes of tetraploid wheat T. turgidum and T. aestivum suggested the following sequence of chromosome rearrangements [51]. The arms $4 \mathrm{AL}$ and 5AL were involved in a reciprocal translocation, T(4AL-5AL)1 [52], produced during the evolution of the A genome, which was transmitted from T. urartu to T. turgidum. This and other chromosome rearrangements are described according to the standard nomenclature [53]. A second reciprocal translocation, T(4AL-7BS)2, and the pericentric inversion of chromosome 4A, $\operatorname{Inv}(4 \mathrm{AS} .4 \mathrm{AL}) 1$, occurred at the tetraploid stage. All of these chromosome rearrangements were transmitted to T. aestivum.

Differentiation of the chromosome structure of wheat genomes was also addressed by physical mapping. More than 60 full-length cDNAs were used as fluorescence in situ hybridization (FISH) probes, whose position was identified in the arms of the 21 chromosomes of hexaploid wheat [47]. Markers were selected to produce three different signals per chromosome arm located in proximal, intercalary and distal positions, respectively. Most of these probes hybridized to all of the three wheat homoeologs. The order and relative positions of the markers was similar in all chromosome arms, except in chromosome arms 2AS, 4AS, 4AL, 4BL, 6AS and 7BS. Such exceptions are the result of the evolutionary rearrangements of $4 \mathrm{~A}, 5 \mathrm{AL}$ and $7 \mathrm{BS}$, as indicated above, or the chromosome rearrangements which appeared in Chinese Spring and other cultivars.

A genetic map of wheat chromosomes, which was based on the arm location of 800 restriction fragment length polymorphism (RFLP) markers using aneuploidy stocks, confirmed the chromosome rearrangements detected with chromosome pairing [48]. Construction of linkage maps involving homoeologous group 4, 5 and 7 chromosomes revealed the presence of a paracentric inversion on chromosome arm 4AL, Inv(4AL.4AL)1 [49,54]. The use of the deletion stocks of wheat [55] allowed us to establish the distribution of different RFLPs markers along the wheat group 4 chromosomes, and a more precise identification of rearranged segments on chromosome $4 \mathrm{~A}$, as well as a pericentric inversion on chromosome 4B [56]. Using nulli-tetrasomic and ditelosomic lines and the deletion set of wheat group 4 chromosomes, the distribution of 1,918 expressed sequence tag (EST) loci along different bins of chromosomes $4 \mathrm{~A}, 4 \mathrm{~B}$ and $4 \mathrm{D}$, was reported [57]. In addition to the identification of inversions Inv(4AS.4AL) and Inv(4AL.4AL)1 and the translocated segments from 5AL and 7BS, another pericentric inversion, $\operatorname{Inv}(4 \mathrm{AS} .4 \mathrm{AL}) 2$, was detected on chromosome $4 \mathrm{~A}$. Comparison of genome sequences of Ae. tauschii and wild T. turgidum ssp. dicoccoides was employed to identify the breakpoints in the rearrangements of chromosome 4A, 5A and 7B [52]. The breakpoints harboring the pericentric inversion Inv(4AS.4AL) 1 were located in sequences containing satellite DNA, while those of reciprocal translocations $\mathrm{T}(4 \mathrm{AL}-5 \mathrm{AL})$ and $\mathrm{T}(4 \mathrm{AL}-7 \mathrm{BS})$ were situated in non-repeated DNA sequences. The breakpoints of the paracentric inversion Inv(4AL.4AL)1 overlapped with the breakpoints of Inv(4AS.4AL)1 and translocation T(4AL-7BS), which suggested that these three rearrangements occurred simultaneously. The breakpoints of pericentric inversion Inv(4AS.4AL)2 were not identified.

The shotgun sequence obtained from individual chromosome arms of Chinese Spring provided a map of 551 homoeologous genes, which denoted the presence of pericentric inversions in at least 10 of the 21 chromosomes [58]. It is likely that some of such rearrangements occurred during the production of the aneuploid lines used in the study. A mapping population of 445 recombinant inbred lines (RILs) obtained from the cross of durum wheat cv. 'Langdon' $x$ wild emmer was developed 
and genotyped with single nucleotide polymorphism (SNP) markers to construct a high-density map of 2,650 segregating markers. An alignment of SNP markers in T. turgidum compared to that in Brachypodium distachyon, rice and sorghum, revealed the presence of 15 structural chromosome rearrangements, in addition to the already known rearrangements [59].

Intra-chromosomal translocations of short segments, a reciprocal translocation between $3 \mathrm{~B}$ and $6 \mathrm{~B}$, a non-reciprocal translocation of a short 6BS segment to 7BL, and three large and one small paracentric inversions, were discovered. Genetic diversity in the rearranged chromosome $4 \mathrm{~A}$ showed that the rearrangements could occur in the primitive tetraploid wheat.

Minor chromosome rearrangements due to gene locus deletion or gene locus duplication were detected in a sample of 3,159 Chinese Spring A- and D-genome gene loci. Such microsynteny perturbations occurred at both the diploid and polyploid levels, and showed a non-random distribution. Their occurrence correlated positively with the distance of the locus from the centromere [10].

Comparative studies revealed significant macro-collinearity between cereal genomes supporting that rice, sorghum and Triticeae originated from a common ancestor with a basic number of $x=12$ chromosomes [60]. Rice maintains this chromosome number, but a reduction to $x=10$ and $x=7$ occurred in the divergence of sorghum and the ancestor of Triticeae, respectively. Comparison of the genome of Ae. tauschii with the rice and sorghum genomes revealed different chromosome rearrangements produced in the evolution of sorghum and Triticeae, and that reduction of the chromosome number was mainly produced by insertion of an entire chromosome in a break produced in the pericentromeric region of another chromosome. In some instance, the inserted chromosome underwent telomeres fusion accompanied with a break in the pericentromeric region [61]. Of 50 rearrangements detected, 40 were assigned to the Ae. tauschii lineage, while two and eight occurred in the evolution of rice and sorghum, respectively. This result suggested a more accelerated evolution of the large genome of the Triticeae species.

\subsection{T. timopheevii}

Sequential N-banding and in situ hybridization revealed two intergenomic translocations present in T. timopheevii [62]. These and other translocations were evidenced from chromosome pairing analysis in the hybrids between T. turgidum and T. timopheevii (AA ${ }^{\mathrm{t} B G}$ ), between T. aestivum and T. timopheevii (AA ${ }^{t} \mathrm{BGD}$ ) and between T. aestivum and T. turgidum (AABBD) $[63,64]$. Chromosomes $1 A^{t}, 2 A^{t}, 5 A^{t}, 7 A^{t}, 2 G, 3 G, 5 G$ and $6 G$ do not structurally differ from their counterparts of the A and $B$ genomes. The remaining chromosomes are involved in five reciprocal translocations: $T\left(4 \mathrm{~A}^{t} \mathrm{~L}-5 \mathrm{~A}^{t} \mathrm{~L}\right)$, which was inherited from $T$. urartu, and translocations $T\left(6 \mathrm{~A}^{\mathrm{t} S}-1 \mathrm{GS}\right), \mathrm{T}(1 \mathrm{GS}-4 \mathrm{GS}), \mathrm{T}\left(4 \mathrm{GS}-4 \mathrm{~A}^{\mathrm{t}} \mathrm{L}\right)$ and $T\left(4 A^{t} L-3 A^{t} L\right)$, which were produced at the tetraploid stage, probably in that sequence. While $A-A$ and $A-A^{t}$ chromosome associations showed similar frequencies in interspecific hybrids, B-B associations were more frequent than B-G associations, denoting a higher differentiation of the $B$ and $G$ genomes relative to the $\mathrm{A}$ and $\mathrm{A}^{\mathrm{t}}$ genomes. This behavior in addition to differences in the chromosome structure between T. turgidum and T. timopheevii support a diphyletic origin of these two tetraploid species. Comparative mapping using microsatellite markers confirmed the presence of translocation $\mathrm{T}\left(6 \mathrm{~A}^{\mathrm{t}} \mathrm{S}-1 \mathrm{GS}\right)[65,66]$, and revealed a paracentric inversion on $6 \mathrm{~A}^{\mathrm{t}} \mathrm{L}$ [65]. Genetic maps with a higher density are required for a more reliable knowledge of the structure of the $\mathrm{A}^{\mathrm{t}}$ and $\mathrm{G}$ genomes.

\subsection{The Sitopsis Section of the Genus Aegilops}

Different studies have been reported on the chromosome structure of Ae. longissima $\left(\mathrm{S}^{\mathrm{l}} \mathrm{S}^{\mathrm{l}}\right)$, Ae. sharonensis $\left(\mathrm{S}^{\mathrm{sh}} \mathrm{S}^{\mathrm{sh}}\right)$, and Ae. speltoides (SS), but little is known in the other two species of the Sitopsis section, Ae. bicornis and Ae. searsii. Chromosome pairing analysis in hybrids of hexaploid wheat and Ae. longissima showed that the arms $4 S^{l} \mathrm{~L}$ and $7 \mathrm{~S}^{\mathrm{l}} \mathrm{L}$ are involved in an evolutionary translocation, while $4 S^{l} S$, $7 S^{l} S$ and chromosome arms $1 S^{1}, 2 S^{1}, 3 S^{1}, 5 S^{1}$ and $6 S^{1}$ show normal homoeology to wheat $[67,68]$. Chromosomes of Ae. sharonensis and Ae. speltoides and their arms show normal homoeologous relationships to wheat as based on the wheat-Aegilops chromosome pairing [69,70]. 
A comparative map of 67 RFLP loci constructed in Ae. longissima confirmed that chromosomes 1S, $2 \mathrm{~S}^{1}, 3 \mathrm{~S}^{1}, 5 \mathrm{~S}^{\mathrm{l}}$ and $6 \mathrm{~S}^{\mathrm{l}}$, the arms $4 \mathrm{~S}^{\mathrm{l} S}$ and $7 \mathrm{~S}^{\mathrm{l}} \mathrm{S}$, and the proximal regions of $4 \mathrm{~S}^{\mathrm{l}} \mathrm{L}$ and $7 \mathrm{~S}^{1} \mathrm{~L}$ are collinear with wheat D-genome chromosomes, and that the distal part of $4 S^{l} \mathrm{~L}$ was translocated from ${ }^{7} \mathrm{~S}^{l} \mathrm{~L}$ [71].

A linkage map of Ae. sharonensis based on 377 Diversity Array Technology (DArT) and 12 simple sequence repeat (SSR) markers comprised 10 linkage groups, four of which were collinear with wheat chromosomes, and assigned to chromosomes $1 S^{\text {sh }}, 2 S^{\text {sh }}, 3 S^{\text {sh }}$ and $6 S^{\text {sh }}$ [72]. A further linkage map constructed with 727 oligo pool assay (OPA) markers allowed to assign the seven linkage groups to chromosomes $1 S^{\text {sh }}$ to $7 S^{\text {sh }}$. Comparison of the OPA marker sequences with the barley genome sequences indicated that chromosomes of both species are highly collinear [73], which is in agreement with normal homoeologous relationships of the $S^{\text {sh }}$ genome chromosomes to wheat. On the other hand, a genetic map of 137 loci constructed in Ae. speltoides compared to that of T. monococcum confirmed that the $S$ genome conserves the gross chromosome structure of wheat [74].

\subsection{Other Aegilops Species}

Exploration of the chromosome structure in other Aegilops species has been based on genetic mapping and, in some instance, on physical mapping of low copy DNA sequences. Construction of a linkage map in Ae. umbellulata (UU), which was based on RFLP loci previously mapped in bread wheat, revealed that multiple chromosome rearrangements occurred in the evolution of this species. The $U$ genome underwent a minimum of 11 reciprocal translocations and inversions to arrive at its current structure [75]. Additional possible rearrangements involving chromosomes $2 \mathrm{U}, 5 \mathrm{U}$ and $6 \mathrm{U}$ were supported by macrosyntenic comparisons of wheat and Ae. umbellulata chromosomes based on the chromosomal assignment of Conserved Orthologous Set (COS) markers in both species [76].

The M genome of Ae. comosa underwent some rearrangements relative to wheat. Chromosome $2 \mathrm{M}$ carries some genetic material from $5 \mathrm{M}$, and a segment from $7 \mathrm{M}$ is present on $3 \mathrm{M}$ [76]. However, the $\mathrm{M}$ genome poses a chromosome structure more similar to that of wheat than the $\mathrm{U}$ genome.

A FISH map of 121 cDNA probes, with an average of 18 markers per chromosome, revealed the presence of evolutionary rearrangements in Ae. markgrafii (syn. Ae. caudata, genome CC) [77]. Chromosomes $1 \mathrm{C}$ and $5 \mathrm{C}$ are collinear to wheat chromosomes 1D and 5D. The other five chromosomes are highly rearranged. The density of markers per chromosome arm made possible to determine the positions of at least 19 breakpoints, which flanked adjacent rearranged chromosome segments with preserved synteny. Rearrangements consisted of pericentric inversions (chromosomes 2C, 3C, 4C and 6C), intra-chromosomal translocations (2C, 3C, 6C and 7C) and inter-chromosomal translocations between $2 \mathrm{C}-4 \mathrm{C}, 3 \mathrm{C}-4 \mathrm{C}$ and $6 \mathrm{C}-7 \mathrm{C}$. In addition, one duplicated segment was found on chromosomes 6C and 7C, and three deletions on chromosomes $4 \mathrm{C}$ and $6 \mathrm{C}$.

\subsection{Rye}

Chromosome pairing analysis of $p h 1 b$ wheat $\mathrm{x}$ rye hybrids carrying diagnostic arm-specific C-banding markers showed normal homoeology of the rye chromosome arms 1RS, 1RL, 2RL, 3RS, $4 R S$ and 5RS to wheat chromosomes. In contrast, 2RS, 3RL, 4RL, 5RL, 6RS, 6RL, 7RS and 7RL paired with wheat chromosomes from a different homoeologous group, denoting they were involved in evolutionary translocations [78,79]. A segment of 2RS showed some homoeology to 6AS, 6BS and 6DS, a distal segment of 3RLwas translocated from 6RL, 4RL carries a distal segment from 6RS and an intercalary segment from 7RS, a long distal segment of 5RL was translocated from 4RL, 6RL carries genetic materials from 3RL and 7RL, chromosome arm 7RS carries a translocated segment from 5RL, and 7RL contains some genetic material from 2RS.

A genetic map of rye constructed with RFLP markers confirmed the implication of six chromosomes in evolutionary rearrangements. Only chromosome $1 \mathrm{R}$ preserves the ancestral structure. Six translocations and one inversion were proposed to occur [80]. Later, a high-density linear gene-order map was established from combining a high-throughput transcript map covering $72 \%$ of the rye genes with chromosome survey sequencing. Seventeen conserved chromosome segments collinear with 
barley and wheat genomes were defined, and the sequence of translocations needed to reach this structure was suggested [9].

\subsection{Barley}

The first analysis of the barley chromosome structure relative to wheat was based on the compared positions of over 100 RFLP loci in the linkage maps of T. monococcum and barley [81]. The synteny of the $\mathrm{A}^{\mathrm{m}}$ and $\mathrm{H}$ genomes was shown to be highly conserved. They differ in the translocation $\mathrm{T}$ (4AL-5AL) present in T. monococcum and in two paracentric inversions that involve the long arm of group 1 and 4 chromosomes. A further reported genetic map constructed using 242 EST and 96 RFLP markers from barley confirmed structural differences detected between the long arms of group 4 and 5 chromosomes [82]. Assembly of 21,766 genes in a linear order and its comparison with high-density physical maps of the wheat A, B and D genomes, showed macro-synteny perturbation because of translocations involving chromosome arms $4 \mathrm{AL}, 5 \mathrm{AL}$ and $7 \mathrm{BS}$, pericentric inversions produced in chromosomes 4A, 5A, 2B and 3B, and the absence of some homoeologous segments in chromosome arms 1AS, 1AL, 2AL, 2DL, 5AL, 5BL and 5DL [83]. In addition, a pericentric inversion was assumed to have occurred in chromosome $1 \mathrm{H}$ after divergence of the barley lineage. A high-quality reference genome assembly for barley was later reported [84].

\subsection{Other Triticeae Species}

Among wild Triticeae species, the crested wheatgrass, Agropyron cristatum, shows a high crossability with wheat and other species, and represents a potential source of genes controlling resistance to biotic and abiotic stresses. The homoeology relationships of the diploid A. cristatum (PP) chromosomes to wheat was analyzed by the FISH locations of 45 wheat full-length cDNA probes in the seven chromosomes of A. cristatum [85]. Chromosomes 1P, 3P and 5P seem to be collinear with wheat chromosomes, while the other four chromosomes show a collinearity distortion, such as a pericentric inversion on $4 \mathrm{P}$, a paracentric inversion on $6 \mathrm{PL}$, or a reciprocal translocation between 2PS and 4PL.

The genus Leymus includes about 30 allotetraploid species that share genomes Ns and Xm derived from Psathyrostachys and an unknown progenitor, respectively. Useful agronomically-important traits have been introduced in wheat, but the homoeologous relationships of the 14 Leymus chromosomes to wheat have not been identified. A genetic map containing 799 EST markers was constructed from fertile hybrids between both of the wild rye species L. triticoides and L. cinereus. Alignments of EST Leymus markers to barley EST maps evidenced the presence of a reciprocal translocation between $4 \mathrm{NsL}$ and $5 \mathrm{NsL}$, which is absent in the Xsm genome [86].

Thinopyrum bessarabicum (JJ) is a diploid perennial maritime wheatgrass with genes for salt tolerance and diseases resistance that can be used in wheat breeding. The physical location of 1150 SNP markers into 36 segments of the seven J chromosomes allowed us to construct a high-density molecular markers map. Synteny analysis with wheat evidenced rearrangements in the J genome, such as a reciprocal translocation between 4JL and 5JL, an interchange between centromeric segments of 2J and $5 \mathrm{~J}$, an intra-chromosomal translocation on 6JL, and a paracentric inversion on 7JS [87].

Intermediate wheatgrass (Thinopyrum intermedium) is a highly productive cool-season forage grass with resistance to drought, frost and many pests and diseases of wheat and other cereals. In addition, this species was identified as a good candidate for domestication and breeding as a perennial grain. Th. intermedium is an allohexaploid $(2 n=6 x=42)$ whose most likely progenitors are the diploid species of Thinopyrum and Pseudoregneria. There are several proposed genome designations, one of which was $\mathrm{Jv}^{\mathrm{vs}} \mathrm{J}^{\mathrm{vs}} \mathrm{J}^{\mathrm{r}} \mathrm{J}^{\mathrm{S}} \mathrm{StSt}$, where $\mathrm{J}^{\mathrm{vs}}$ and $\mathrm{J}^{\mathrm{r}}$ represent ancestral genomes of the extant Th. bessarabicum and Th. elongatum species, respectively, and St the genome of some diploid species of Pseudoroegneria from Eurasia [88]. Genotyping-by-sequencing was used to construct a genetic map containing 10,029 markers distributed among the 21 linkage groups of Th. intermedium [89]. Comparison of the 21 linkage groups of intermediate wheatgrass with the barley reference genome sequence evidenced three highly collinear homoeologous genomes syntenic with the barley genome with only one exception, 
a reciprocal translocation between two chromosomes homoeologous to $4 \mathrm{H}$ and $5 \mathrm{H}$. This translocation was suggested to belong to the St genome, but the chromosome structure of the Th. bessarabicum genome is consistent with a translocation inherited from the donor of the $\mathrm{J}^{\mathrm{vs}}$ genome.

\subsection{Recurrence and Variable Frequency of Chromosome Rearrangements}

Evolutionary chromosome rearrangements vary between the species studied. However, the reciprocal translocation between $4 \mathrm{~L}-5 \mathrm{~L}$ is present in different diploid and polyploid species. Because of the discovery of this translocation in wheat and rye, a possible monophyletic origin of this translocation in a common ancestor of both lineages was rejected, since the D genome of wheat, which is more closely related to the A genome than the R genome, does not carry this translocation [90]. This translocation is also absent in the genomes of the Aegilops species including Ae. tauschii, Ae. speltoides and Ae. sharonensis. This suggests independent origins for translocation $4 \mathrm{~L}-5 \mathrm{~L}$ in different lineages. Accordingly, although in rye and wheat the breakpoint positions are identical on $4 R L$ and $4 A L$, they are different on 5RL and 5AL [91]. These sites were suggested to occupy chromosome rearrangements hotspots, as they coincide with inversion junctions produced in the Triticeae ancestor [91].

On the other hand, variation in the number of gross chromosome rearrangements among different species suggests that the chromosome structure does not evolve parallel to its genome differentiation. For example, despite the theory that Hordeum diverged much earlier than Aegilops, barley, Ae. tauschii, Ae. speltoides and Ae. sharonensis show a highly conserved synteny. In contrast, rye, Ae. umbellulata and Ae. caudata, all of which diverged later than Hordeum, underwent a considerable number of chromosome rearrangements. Two of these species, rye and Ae. caudata, have been shown to undergo introgressive hybridization during their evolution, which is considered the source of their highly rearranged genomes $[9,77]$. The role of interspecific hybridization on genome reorganization is also apparent in the formation of allopolyploids. Chromosome rearrangements produced in tetraploid wheats contrast the highly conserved synteny of their diploid progenitors. Allopolyploidy is usually accompanied by extensive genome reorganization and changes in gene expression within a short period of time in wheat and other plant lineages. Both the genetic control of pairing and the physical divergence of the homoeologous genomes are considered the genetic systems responsible for the cytological diploidization of polyploid wheat [92,93]. Consequently, interspecific hybridization appears as a releasing factor of genome reorganization, which may accelerate the diploidization of allopolyploids. When recurrent polyploid formation is accompanied with variable genome rearrangements, as in tetraploid wheats, structural chromosome differentiation may hinder the genetic flow between the polyploids of different origins and facilitate their speciation.

\section{An Overview on Meiotic Recombination in Plants}

Meiotic recombination is the cellular process that generates new allele combinations upon which natural or artificial selection can act to favor the establishment of better adapted genotypes, or more useful agronomical traits, respectively. Plant breeders search for novel varieties, which combine valuable traits present in different parental lines. The genetic information provided by both parents is reshuffled in the F1 hybrid meiosis, and genetic combinations of interest appear in the offspring. When traits of interest are controlled by non-linked genes, the searched gene combination is the result of random chromosome segregation at the anaphase I of the hybrid. In the case of joining alleles present in homologous (or homoeologous) chromosomes, intra-chromosomal homologous (or homoeologous) recombination is required. Intra-chromosomal homologous recombination is produced during the first meiotic division as a result of the repairing process triggered at leptotene by a programmed production of double-strand DNA breaks (DSBs) catalyzed by the topoisomerase-like SPO11 protein [94,95]. The repairing process is configured over an intact template that may reside in the sister chromatid or in a chromatid of the homologous partner. There is evidence that both pathways exist in meiosis, although meiotic chromosomes seem to be organized to facilitate the choice of homologous recombination [96]. Nucleo-filaments formed by $3^{\prime}$ single-strand DNA overhangs 
generated from each DSB bound to recombinases RAD51 and DMC1 to invade a double-strand DNA stretch of the homologous chromosome to find its complementary strand [97]. The use of a non-sister homologous template may culminate with either a reciprocal exchange of large homologous chromosome segments, i.e., a crossover (CO), or the non-reciprocal exchange of a small DNA sequence, i.e., a non-crossover (NCO).

The DSBs repairing process is broadly conserved among plants, and comprehensive insights on the underlying molecular mechanism have been provided in recent reviews [98-100]. Only a minor fraction (5\% in Arabidopis, or maize) of the homologous interactions are resolved as COs. This is enough to ensure the occurrence of at least one $\mathrm{CO}$, the obligatory $\mathrm{CO}$, per chromosome pair. Most COs are processed in the class I pathway, which relies on a group of proteins called ZMMs (SHOC1/ZIP2, HEI10, ZIP4, MER3, MSH4, MSH5 and PTD) and two additional proteins MLH1 and MLH3 not included in the ZMM group [98]. A feature of the class I COs is that they prevent the occurrence of additional COs nearby. Class II COs are dependent upon structure-specific endonucleases including MUS81, and are insensitive to interference [101]. In addition to these two pathways that lead to the CO production, other mechanisms are involved in DSBs repairing. Three other groups of proteins are involved in the restriction of the CO number [99,100,102]: (i) FANCM and its cofactors MHF1 and MHF2 are thought to unwind post-invasion intermediates to promote NCOs through the synthesis-dependent strand annealing (SDSA) pathway, (ii) the BLM/Sgs1 helicase homologs RECQ4A/RECQ4B and the associated proteins TOP $3 \alpha$ and RMI1, which process probably different recombination intermediates of FANCM, and (iii) FIGL1 and its partner FLIP, which may control the activity of the recombinases RAD51 and DMC1. Mutations that disrupt any of these three NCOs promoter pathways increase the frequency of class II COs dependent of MUS81 in Arabidopsis [102]. Recombination frequency increases with the distance to the centromere, and reaches maximum values in distal regions.

Regular segregation of homologous chromosomes at anaphase I is facilitated by the formation of chiasmata, which are visible from diplotene to metaphase I and represent the cytological expression of COs produced in previous stages. The occurrence of a $\mathrm{CO}$ between homologous chromatids happens in a context in which each member of the partner and its sister chromatid are held together by a number of ring-shaped cohesin complexes scattered along the chromosomes axes and formed after DNA replication. The cohesin complexes also play an additional role in the DSBs repairing process [103]. Cohesion is released from chromosome arms at anaphase I, but not from the centromere region, where sister kinetochores remain associated and oriented to the same pole [104]. Connections between sister kinetochores are resolved at anaphase II, allowing their segregation to opposite poles.

In most species, COs are non-randomly distributed along chromosomes. They are clustered at recombination hotspots that alternate with poor recombination domains. Initial steps of recombination are to some extent responsible for the CO distribution, but it is not clear whether the CO landscape mirrors the non-uniform DSBs' positioning [105]. High-resolution maps of recombination events in plants show COs located in regions close to gene promoters and terminators [106]. While the DSB and CO maps are rather similar in Arabidopsis [107], they are very different in maize [108]. Only a quarter of DSBs produced in maize occur near genic regions, and can be processed as COs, the remaining DSBs situate in repetitive DNA, and do not form COs. Different patterns of CO distribution have been reported in plants. The most common situation is a pronounced localization in a distal euchromatic region. This is the case of maize [109] and Triticeae species [26,110-113], with an extremely distal location in Ae. speltoides [74]. Some species show a quite different pattern, for example, CO hotspots extend throughout the entire chromosome in Arabidopsis and rice [99], while most COs are located in the proximal quarter of the Allium fistulosum chromosomes [114].

Preferences for $\mathrm{CO}$ location in euchromatic regions suggest a specific role of chromatin structure in the recombination distribution. In fact, $\mathrm{CO}$ hotspots have low DNA methylation and transposons in some cereals [98]. In Arabidopsis, COs and recombination are correlated with active chromatin features, such as the modified histone H2A.Z, trimethylation of histone H3 on lysine 4 (H3K4me3), low DNA 
methylation, and low-nucleosome-density regions $[115,116]$. Epigenetic marks are also responsible for the absence of COs in centromeres and the surrounded heterochromatic regions of plant chromosomes.

Modification of pericentromeric epigenetic marks, such as histone 3 lysine 9 dimethylation (H3K9me2), and DNA methylation in CG and non-CG sequences in Arabidopsis defective mutants for the H3K9 methyltransferase genes KYP/SUVH4 SUVH5 SUVH6, or the CHG DNA methyltransferase gene CMT3, increases CO frequency in proximal regions, despite the fact that the total number of COs is not affected [117]. In addition to chromatin structure, the initiation of recombination changes across the telomere-centromere axis. DSBs appear initially in sub-telomeric CO-rich regions, and extend later to the intercalary CO-poor regions of barley chromosomes [113], which suggests that early recombination events are preferred for $\mathrm{CO}$ formation.

Homoeologous chromosomes are present in interspecific hybrids and allopolyploids, and represent potential partners to be involved in the DSBs' repairing process. Such chromosome partner selection was found to be suppressed in hexaploid wheat by the action of the Ph1 locus of chromosome 5B [36,37]. $P h 1$ was first assigned to a structure composed of a segment of heterochromatin inserted into a cluster of seven cyclin-like-dependent kinase (CDK) genes [118]. This Ph1 assignment was later put into question by the meiotic phenotype of a different candidate gene, $C-P h 1$, which was silenced [119]. Included in the heterochromatin segment of chromosome 5B is the ZMM gene ZYP4 (TAZYP4-B2). This gene was proposed to be $P h 1$, as supported by the high level of homoeologous pairing found in the hybrids of two Tazyp4-B2 TILLING mutants and one CRISPR mutant of wheat with Ae. variabilis [120,121]. In addition, extensive analysis of RNA seq data in wheat, wheat $x$ rye hybrids and triticale with and without $P h 1$, indicated that the silenced C-ph1 gene corresponded to a copy present on chromosome 5D, since the copy on chromosome 5B is not expressed at any meiosis stage [122]. Ph1 is the most effective suppressor gene of homoeologous recombination in polyploid wheats. Ph2, another suppressor located on chromosome arm 3DS, shows an intermediate effect [123]. Two main steps of bivalents' formation seem to be under the action of Ph1: The suppression of recombination between homoeologous chromosomes, despite the fact that they form synaptonemal complex (SC) during zygotene, and the correction of SC multivalents to form two or more bivalents during pachytene [124]. However, how this can be accomplished is poorly understood.

\section{Modulating the Meiotic Recombination Landscape for Cereal Improvement}

The reference sequence of the wheat genome gives access to 107,891 genes, with an uneven distribution along the chromosomes [26]. Intercalary CO-poor regions harbor a larger fraction of genes than the highly recombinogenic distal regions. A similar genome organization is present in barley [84]. Increasing recombination in chromosome regions with low $\mathrm{CO}$ frequency is upmost in importance from the breeding perspective. A possible strategy would be to increase the overall $\mathrm{CO}$ frequency using anti-CO mutants. The TILLING mutants generated in tetraploid and hexaploid wheats, which are accessible in public databases [125], may be very useful for this purpose. Mutation of anti-CO genes greatly increase the $\mathrm{CO}$ frequency in Arabidopsis and in crops such as Brassica, rice, pea and tomato [106]. However, this strategy may fail in promoting CO in low-recombining regions of crops because, in Arabidopsis, extra COs fall into the highly recombining regions [102]. Approaches, such as manipulation of epigenetic marks associated with low recombining regions, or the induction of DSBs at specific chromosome sites by a fusion of SPO11 and different DNA-binding proteins, have been proposed to increase the CO number in intercalary or proximal regions [106]. Available stocks of wheat mutants [125] can also be used for the identification of candidate genes involved in chromatin organization, which might have some effect on meiotic recombination.

An alternative approach may be based on the environmental effect on meiotic development. A number of exogenous factors, including environmental stresses, agrochemical, heavy metals, combustible gases, pharmaceutical and pathogens, are known to affect meiosis in plants [126]. Many of these factors produce meiotic abnormalities such as laggards, univalents, bridges, stickiness, or precocious chromosome movements, which detract their practical value to modify the recombination 
pattern. Special attention has been received on the effect of temperature, which is species-specific. In Arabidopsis, the response to temperature variation follows a U-shaped curve with increased CO frequencies at low $\left(8^{\circ}\right)$ and high $\left(28^{\circ}\right)$ temperatures relative to a medium-range value (18 $)$ [127]. Extra COs produced at extreme temperatures were of the class I pathway. In contrast, barley plants subjected at a temperature of $30^{\circ}$ produce a lower number of chiasmata in male meiosis, which change their positions towards more proximal locations. Repositioning of recombination events affects only the class I COs $[113,128]$. Modification of nutrient concentration also affect the recombination frequency. Among Triticeae, a high phosphate level increases chiasma frequency in rye [129] and magnesium of the Hoagland's solution increases CO frequency in wheat and the hybrids of wheat lacking Ph1 with related species [121]. However, it is unknown whether these nutrients modify the CO distribution or not.

Wild relatives are a source of variation for introgressing crops traits, providing tolerance to biotic and abiotic stresses. Introgression can be achieved through meiotic recombination between homologous chromosomes using wild species that share same genome with the crop. A number of genes providing resistance to diseases and pests were transferred from diploid and polyploid wild Triticum species to cultivated wheats [34,130]. Genetic variability is much higher in wild species containing genomes that are homoeologous to those of the crops. Transfer of useful genes from such species requires the induction of recombination between homoeologous chromosomes of the cultivated and wild species. This homoeologous recombination is induced in the absence of chromosome 5B, or using the deletion mutant ph1b, which lacks Ph1 [131]. This mutant line has the disadvantage of accumulating translocations between homoeologous chromosomes produced by meiotic recombination [132]. However, other mutants of the ZIP4-B2 gene in the Ph1 locus recently obtained, form only homologous bivalents at metaphase I, and preserve better the genome stability [120]. Another way of inducing homoeologous recombination is through the use of genes that suppress the effect of Ph1. Suppressors of Ph1 have been reported in Ae. speltoides and other species. One of the two major suppressor loci of Ae. speltoides, Su1-Ph1, which is located distally on the long arm of chromosome 3S, has been introgressed into chromosome 3A of hexaploid and tetraploid wheats [133] and can be used in interspecific gene transfer.

Pioneer works of wild introgression into wheat via homoeologous recombination were those transferring disease resistance genes from Ae. comosa and Ag. elongatum [134-136]. The transfer of resistance to the yellow rust Puccinia striiformis from Ae. comosa to wheat was induced by the Ae. speltoides genome. Plants homozygous for the resistant allele gave rice to the wheat variety known as Compare $[134,135]$. Recombination between wheat chromosomes 3D and 7D and their homoeologues of $A g$. elongatum, produced in the absence of chromosome 5B, made possible the transfer to wheat of resistance to the leaf rust Puccinia recondita [136]. After these genetic transfers to wheat, many others have been produced. Species of the genus Aegilops represent a valuable source of genetic variability used in wheat improvement. Most Aegilops species were crossed with wheat to obtain amphiploids, and addition, substitution, translocation and segmental introgression lines. More than 40 resistance genes from the Aegilops species have been introgressed into wheat through chromosome translocation or homoeolgous recombination, and some of them have been used in wheat production [40]. An ample genetic variability present in perennial wild grasses and wild ryes has been incorporated also into the wheat genome in the form of amphiploids or derivatives such as addition, substitution or radiation translocation lines, as well as recombinant lines with segmental introgressions. Transfers involving Thinopyrum species have provided valuable contributions in wheat cultivar development [137].

Intercrops transfers have also been employed in some breeding programs. Many efforts have been made to use the gene pool of rye in wheat improvement. The production of hexaploid triticale AABBRR is a representative example of the success of combining the genomes of both species to produce an excellent feed crop. However, the highest potential of rye introgressions into wheat has been manifested in the production of a number of wheat cultivars carrying the wheat-rye translocations 1RS.1BL or 1RS.1AL, with a noteworthy positive effect on yield production [138]. Wheat-barley hybrids 
and introgressions have been produced also [139]. The transfer to wheat of barley genes controlling agronomical traits, such as drought tolerance, high $\beta$-glucan content, salt tolerance or earliness, is conditioned by the low crossability between both species. Efforts should be made to increase the efficiency of the crosses.

Hybrids between wheat and other Hordeum species have also been developed. Tritordeum, a $H$. chilense $\times$ durum wheat amphiploid, is the most successful introgression $[140,141]$. After the improvement of different agronomical traits in field experiments, Tritordeum became a synthetic cereal to some extent comparable to triticale. Recombination between the chromosomes of wheat and $H$. chilense has been induced in the absence of $P h 1$, supporting the idea that the transfer is possible using this approach [142].

In addition to the desirable gene, recombinant chromosomes carrying segments of wheat and alien chromosomes might carry other genes that reduce the agronomical value of the introgression. Therefore, primary recombinant chromosomes should be engineered to remove undesirable genes. This is possible after the production of sets of primary recombinant chromosomes formed by wheat-centromere-wheat/alien genetic material, which differ in the translocation breakpoint position, and their reciprocal counterparts, formed by alien-centromere-alien/wheat genetic material. Double heterozygotes containing chromosomes of the types wheat-centromere-wheat/alien and alien-centromere-alien/wheat, carrying the desirable gene from wild species, that undergo a $\mathrm{CO}$ in the overlapping alien region, produce secondary recombinants wheat-centromere-wheat/alien/wheat with the desirable gene into a shorter alien intercalary segment $[143,144]$. In the absence of such primary recombinant chromosome sets, the size of the translocated alien segment can be reduced in additional rounds of homoeologous recombination between the translocated alien segment and the standard wheat chromosome.

\section{The Impact of Chromosome Rearrangements on Meiotic Recombination}

$\mathrm{CO}$ frequency in Triticeae was estimated to range between two and three COs per chromosome, or more than one CO per chromosomal arm [112,145]. Distal confinement of the site of the first or only $\mathrm{CO}$ in each arm might be conditioned by the subtelomeric location of the initial interactions between homologs imposed by the bouquet arrangement [146]. In fact, distal recombinational events precede those more proximally located in barley [113]. CO interference could condition the formation and position of additional COs. Given the preferred distal localization of COs in many plant species, an alteration of the standard chromosome structure represents an approach used to understand the molecular basis underlying this recombination pattern. Chromosome structural mutants, such as deletions and inversions, which modify the relative position of the genetic material present in a given chromosome, have been produced in wheat, rye and Arabidopsis. In wheat, both types of chromosome mutants are viable in the homozygous and heterozygous conditions, and the same is with rye when the mutant chromosome is introgressed in wheat. Large deletions produced in Arabidopsis are viable only in heterozygotes [147]. Recombination in such heterozygotes denotes no major effect of the deletions in the total number of COs. The loss of COs at the deletion sites is compensated by increases in recombination frequencies elsewhere on the same chromosome. Thus, changes in the physical structure of a given chromosome redistribute the COs within that chromosome [147].

Studies using deletions and inversions in wheat and rye were aimed at verifying the ability of a given region to form $\mathrm{CO}$ after changing its position in the centromere-telomere axis. Heterozygotes for the loss of a long terminal segment of wheat chromosome arms 4AL, 2BL and 5BL underwent a considerable reduction of chiasma frequency at metaphase I in these arms, but the level of chiasmata became normal in homozygotes for the truncated arms [148]. On the other hand, homozygotes for the loss of the distal $25 \%$ of the $1 \mathrm{BL}$ arm, or the distal $41 \%$ of $5 \mathrm{BL}$, increase the recombination rate of the middle arm region, without modifying that of the proximal region, relative to wild type plants $[149,150]$. These results suggest that the position of a segment in the telomere-centromere axis was a decisive factor in its capacity to produce a CO. However, other studies contradict this idea. Regardless, synapsis 
is completed, COs are infrequent in the proximal third of the rye chromosome arm 5RL, both in homozygotes for the standard chromosome $5 \mathrm{R}$, and homozygotes lacking the distal $70 \%$ of its long arm [151]. Even more convincing is the effect of the repositioning from distal to proximal of the highly recombinogenic region of the arms $1 \mathrm{RL}$ of rye and $2 \mathrm{BS}$ and $4 \mathrm{AL}$ of wheat, as a result of large paracentric inversions. COs are restricted to the proximal region in all homomozygotes for the inversion [152-154].

Thus, CO distributions in the arms 4AL and 2BS of wheat and 1RL and 5RL of rye are not dependent of the distance to the telomere; other factors such the DNA sequence and the pattern of chromatin organization should condition the recombination landscape.

Given that the truncation of chromosome arms 1BL and 5BL increases the frequency of recombination in their middle region [149,150], a similar effect was expected in other chromosomes of wheat. Progressive shortening of the arms of wheat chromosomes $4 \mathrm{~A}$ and those of the $\mathrm{B}$ genome by terminal deletions showed an apparent shift of the $\mathrm{CO}$ site from distal to middle-proximal regions [155]. Chiasmate associations at metaphase I of the truncated homologous arms estimated the $\mathrm{CO}$ frequency in the fraction of the arms present in homozygotes for terminal deletions of different size. According to the preferred distal localization of COs, a decrease in the $\mathrm{CO}$ frequency accompanied the progressive reduction of the arm length. The recombination level of the standard chromosome was not recuperated in most deletions, but a considerable increase in the middle chromosome arm regions was supported. Deletions with breakpoints in sub-distal sites in chromosome arms del2BS, del2BL and del6BS show higher $\mathrm{CO}$ frequencies than deleted arms with more distal breakpoints. Most of the COs produced in the intact chromosome 3B locate in the distal $68 \mathrm{Mb}(\sim 20 \%$ of the total arm) of 3BS and the distal $59 \mathrm{Mb}(\sim 14 \%$ of the total arm) of 3BL [112]. These chromosome segments are smaller than those missing in deletions 3BS-7 (25\%) and 3BL-11 (19\%). Lines for these two deletions show very high CO frequencies, $66 \%$ the 3BS-7 deletion line and 99\% the 3BL-11 line [153], suggesting that the shortening of the chromosome arm increases the level of recombination in intercalary regions of chromosome 3B. The intercalary deletion of the $p h 1 b$ mutant maps $0.9 \mathrm{cM}$ from the centromere, which corresponds to a CO frequency of 0.018 [156]. Despite that the interval centromere-ph1b deletion is longer than the fraction of the 5BL arm present in the del5BL-5 truncated chromosome, homozygotes for the del5BL-5 deletion form at least one $\mathrm{CO}$ in the deleted arm in $62 \%$ of meiocytes. The increase of $\mathrm{CO}$ frequency in intercalary regions induced by terminal deletions seems to be common to most wheat chromosomes. The 1BS arm represents an exception, since different deletion lines show a low CO frequency. The reason of the $\mathrm{CO}$ redistribution in deletion lines is still unknown, but future research in this field can provide valuable information to modify the recombination landscape.

The frequency of association between the homoeologous arms of individual chromosomes of wheat, and between wheat and related species chromosomes, has been reported in interspecific hybrids of wheat with rye, Ae. longissima, Ae. sharonensis, Ae. speltoides or T. timopheevii [46,63,67-70,78,79]. The long arms of groups 1 and 2 chromosomes of wheat and rye differ in the amount of $C$-heterochromatin present in their subtelomeric regions. Such differences made possible to identify the parental heterochromatin constitution of chromosomes at anaphase I, as well as recombinant wheat-wheat (A-B and B-D) and wheat-rye (A-R, B-R and D-R) homoeologous chromosomes in ph1b ABDR hybrids. The recombinant chromosome ratio fits the frequency of association at metaphase $\mathrm{I}$ in all the different homoeologous arm combinations $[78,157]$. Thus the frequency of association at metaphase I between homoeologous arms represents a good estimate of the homoeologous recombination frequency.

Among bread wheat chromosomes, both arms of chromosome 4A, and the arms 5AL and 7BS are involved in evolutionary chromosome rearrangements. The same happens with rye chromosome arms 2RS, 3RL, 4RL, 5RL, 6RS, 6RL, 7RS and 7RL, which are involved in multiple translocations relative to the wheat $\mathrm{D}$ genome, as well as with the arms $4 S^{l} \mathrm{~L}$ and $7 S^{l} \mathrm{~L}$ of Ae. longissima. In both ph1b mutant wheat $\times$ rye and $p h 1 b$ wheat $\times A e$. longissima hybrids, the frequencies of all possible associations wheat-wheat (A-B, A-D, and B-D), wheat-rye (W-R) and wheat-Ae. longissima (W-S1), are known. Thus, it is possible to assess the effect of chromosome structure on homoeologous recombination by a comparison of the level of recombination between chromosome arms showing normal homoeologous 
relationships and those rearranged during evolution. Mean frequencies of wheat-wheat, wheat-rye and wheat-Ae. longissima associations involving arms with conserved macro-synteny, or arms with gross rearrangements, are given in Table 1.

Table 1. Average frequency (\%) of association at metaphase I between syntenic and rearranged homoeologous arms in hybrids of the ph1b mutant wheat $(\mathrm{W})$ with rye $(\mathrm{R})$ or Ae. longissima $\left(\mathrm{S}^{\mathrm{l}}\right)$.

\begin{tabular}{cccc}
\hline Homoeologous Association & Syntenic Arms & Rearranged Arms & Reference \\
\cline { 1 - 3 } A-B-D & 4.67 & 0.95 & \\
[A-B & 7.68 & 3.55 & \\
\cline { 1 - 3 } A-D & 60.52 & 12.05 & \\
\hline B-D & 17.48 & 0 & [78] \\
\hline W-R & 10.76 & 3.51 & [67] \\
\hline W-S & 56.86 & 25.3 & \\
\hline
\end{tabular}

Although there are differences between short and long arms, as well as between homoeologous groups, on average, chromosome rearrangements cause a considerable reduction of homoeologous recombination, and may represent an obstacle in the transfer of genes located in rearranged chromosome arms. Exceptions are the 5RL arm of rye [78] and the $4 S^{l} \mathrm{~L}$ of Ae. longissima [67], which probably carry long translocated segments.

T. timopheevii chromosomes evolved a different structure from that of T. durum and T. aestivum, despite the theory that the donors of the $\mathrm{A}^{\mathrm{t}}$ and $\mathrm{A}$ genomes, and of the $\mathrm{G}$ and $\mathrm{B}$ genomes, are considered to be T. urartu and Ae. speltoides, respectively, in both lineages [63,64]. All three species share translocation T(4AL-5AL). However, while the inversions in $4 \mathrm{~A}$ and translocation T(4AL-7BS) occurred in T. turgidum, four different translocations involving the arms $3 \mathrm{~A}^{t} \mathrm{~L}, 4 \mathrm{~A}^{t} \mathrm{~L}, 6 \mathrm{~A}^{t} \mathrm{~S}, 1 \mathrm{GS}$ and 4GS appeared in T. timopheevii. The effect of structural differences on the frequency of the $\mathrm{A}^{\mathrm{t}}$-A and G-B associations in interspecific hybrids between these three species is shown in Table 2. There is a considerable reduction of the recombination frequency between arms showing differences in the chromosome structure. The effect is more apparent among the G-B associations, which, on average, are less frequent than the $\mathrm{A}^{\mathrm{t}}$-A associations.

Table 2. Average frequency (\%) of association at metaphase I between syntenic and rearranged chromosome arms of the $\mathrm{A}$ and $\mathrm{A}^{\mathrm{t}}$ genomes and the $\mathrm{B}$ and $\mathrm{G}$ genomes in T. timopheevii $\times$ T. turgidum $\left(\mathrm{A}^{\mathrm{t}} \mathrm{AGB}\right)$ and T. timopheevii $\times$ T. aestivum (A $\left.{ }^{\mathrm{t}} \mathrm{AGBD}\right)$ hybrids.

\begin{tabular}{ccccc}
\hline Hybrids & Association Type & Syntenic Arms & Rearranged Arms & Reference \\
\hline \multirow{2}{*}{ A $^{\mathrm{t}}$ AGB } & $\mathrm{A}^{\mathrm{t}}-\mathrm{A}$ & 93.19 & 54.87 & \\
\cline { 2 - 4 } & $\mathrm{G}-\mathrm{B}$ & 45.89 & 8.5 & [63] \\
\hline \multirow{2}{*}{ A $^{\mathrm{t}}$ AGBD } & $\mathrm{A}^{\mathrm{t}}-\mathrm{A}$ & 89.16 & 57.7 \\
\cline { 2 - 4 } & $\mathrm{G}-\mathrm{B}$ & 27.93 & 7.9 \\
\hline
\end{tabular}

Superimposed to the effect of chromosome structural differentiation on homoeologous recombination is the effect of the level of genetic affinity between cultivated and wild species, which is a result of their phylogenetic relationships. Chromosomes of species very distant in their evolution have a lower frequency of recombination than chromosomes of species with a higher closeness. This is apparent when the results obtained in wheat $\times$ Aegilops and wheat $\times$ rye hybrids are compared (Table 1). Chromosomes of Ae. longissima, Ae. sharonensis and Ae. speltoides, which are more closely related to wheat than to rye chromosomes, recombine with wheat chromosomes, especially with those of the B genome, much more frequently than with rye chromosomes. Accordingly, $\mathrm{A}^{\mathrm{t}}-\mathrm{A}$ 
chiasmate associations are more frequent than $B-G$ associations in $A A^{t} B G$ and $A A^{t} B G D$ wheat hybrids (Table 2). Both conservation of macro-synteny and genetic differentiation are factors conditioning interspecific introgressions.

\section{Concluding Remarks}

Modulating the recombination landscape is of supreme importance for crop breeding, since a considerable number of genes with agronomical relevance are located in crossover-poor chromosome regions. Truncation of wheat chromosomes has been shown as a very useful way of increasing the recombination frequency in their intercalary regions. This approach is, of course, inviable in diploid crops and, most likely, it does not have an immediate application in wheat production. However, it may represent a reference to investigate the reason why such regions produce more COs in the truncated chromosomes than in the standard ones. Homologous and homoeologous recombinations show similar distribution patterns, and therefore, achievements reached in the first are also of interest for the second. A structural differentiation of chromosomes from different species has a negative effect on meiotic recombination between such chromosomes. This is probably a consequence of disturbances on chromosome interactions caused by the absence of synteny. In such cases, introgressions should be carried out using other methods such as radiation. Thus, the chromosome structural organization of related genomes is of interest in designing strategies of the introgression of useful genes into crops. Recent advances in the knowledge of wheat and related species' genomes will facilitate a rapid progress of future research projects aimed to introgress useful agronomical traits into wheat and other crops. Genomic datasets for wheat and some related species, which are of public access (htps://plants.ensambl.org), make possible the analysis of any region with its gene content and the comparison among different species. Expression profiles are available in a considerable number of tissues, including meiotic cells. Thus, expression patterns of genes identified in different species can be compared to homoeologous genes of wheat. This reinforces polyploid wheat as a very powerful model system for study, propelling it into the mainstream of the global plant research community.

Author Contributions: T.N. designed and wrote the work.

Funding: This work was supported by grant AGL2015-67349-P from Dirección General de Investigación Científica y Técnica, Ministerio de Economía y Competitividad of Spain.

Conflicts of Interest: The author declares no conflict of interest.

\section{References}

1. Bernhardt, N. Taxonomic treatments of Triticeae and the wheat Genus Triticum. In Alien Introgression in Wheat. Cytogenetics, Molecular Biology and Genomics; Molnár-Láng, M., Ceoloni, C., Doležel, J., Eds.; Springer: Berlin/Heidelberg, Germany, 2015; pp. 1-19. [CrossRef]

2. Feldman, M.; Levy, A.A. Origin and evolution of wheat and related Triticeae species. In Alien Introgression in Wheat. Cytogenetics, Molecular Biology, and Genomics; Molnár-Láng, M., Ceoloni, C., Doležel, J., Eds.; Springer: Berlin/Heidelberg, Germany, 2015; pp. 21-76. [CrossRef]

3. Gaut, B.S. Evolutionary dynamics of grass genomes. New Phytol. 2002, 154, 15-28. [CrossRef]

4. Huang, S.; Sirikhachornkit, A.; Su, X.; Faris, J.; Gill, B.; Haselkorn, R.; Gornicki, P. Genes encoding plastid acetyl-CoA carboxylase and 3-phosphoglycerate kinase of the Triticum/Aegilops complex and the evolutionary history of polyploid wheat. Proc. Natl. Acad. Sci. USA 2002, 99, 8133-8138. [CrossRef]

5. Eilam, T.; Anikster, Y.; Millet, E.; Manisterski, J.; Feldman, M. Genome size in natural and synthetic autopolyploids and in a natural segmental allopolyploid of several Triticeae species. Genome 2009, 52, 275-285. [CrossRef] [PubMed]

6. Blattner, F.R. Progress in phylogenetic analysis and a new infrageneric classification of the barley genus Hordeum (Poaceae: Triticeae). Breed. Sci. 2009, 59, 471-480. [CrossRef]

7. The International Barley Genome Sequencing Consortium. A physical, genetic and functional sequence assembly of the barley genome. Nature 2012, 491, 711-716. [CrossRef] [PubMed] 
8. Maraci, Ö.; Özkan, H.; Bilgin, R. Phylogeny and genetic structure in the genus Secale. PLoS ONE 2018, 13, e0200825. [CrossRef] [PubMed]

9. Martis, M.M.; Zhou, R.; Haseneyer, G.; Schmutzer, T.; Vrána, J.; Kubaláková, M.; Konig, S.; Kugler, K.G.; Scholz, U.; Hackauf, B.; et al. Reticulate evolution of the rye genome. Plant Cell 2013, 25, 3685-3698. [CrossRef] [PubMed]

10. Dvorak, J.; Akhunov, E.D. Tempos of gene locus deletions and duplications and their relationship to recombination rate during diploid and polyploid evolution in the Aegilops-Triticum alliance. Genetics 2005, 171, 323-332. [CrossRef] [PubMed]

11. Marcussen, T.; Sandve, S.R.; Heier, L.; Spannagl, M.; Pfeifer, M.; The International Wheat Genome Sequencing Consortium; Jakobsen, K.S.; Wulff, B.B.H.; Steuernagel, B.; Klaus, F.X.; et al. Ancient hybridizations among the ancestral genomes of bread wheat. Science 2014, 345. [CrossRef] [PubMed]

12. Gornicki, P.; Zhu, H.; Wang, J.; Challa, G.S.; Zhang, Z.; Gill, B.S.; Li, W. The chloroplast view of the evolution of polyploid wheat. New Phytol. 2014, 204, 704-714. [CrossRef] [PubMed]

13. Dvorak, J.; di Terlizzi, P.; Zhang, H.B.; Resta, P. The evolution of polyploid wheats: Identification of the A genome donor species. Genome 1993, 36, 21-31. [CrossRef] [PubMed]

14. Sarkar, P.; Stebbins, G.L. Morphological evidence concerning the origin of the B genome in wheat. Am. J. Bot. 1956, 43, 297-304. [CrossRef]

15. Dvorak, J.; Zhang, H.B. Variation in repeated nucleotide sequences sheds light on the phylogeny of the wheat B and G genomes. Proc. Natl. Acad. Sci. USA 1990, 87, 9640-9644. [CrossRef] [PubMed]

16. Kihara, H. Discovery of the DD-analyser, one of the ancestors of Triticum vulgare. Agric. Hortic. 1944, 19, $13-14$.

17. McFadden, E.S.; Sears, E.R. The origin of Triticum spelta and its free-threshing hexaploid relatives. J. Hered. 1946, 37, 81-89. [CrossRef] [PubMed]

18. Ogihara, Y.; Tsunewaki, K. Diversity and evolution of chloroplast DNA in Triticum and Aegilops as revealed by restriction fragment analysis. Theor. Appl. Genet. 1988, 76, 321-332. [CrossRef] [PubMed]

19. Terachi, T.; Ogihara, Y.; Tsunewaki, K. The molecular basis of genetic diversity among cytoplasms of Triticum and Aegilops. 7. Restriction endonuclease analysis of mitochondrial DNA from polyploid wheats and their ancestral species. Theor. Appl. Genet. 1990, 80, 366-373. [CrossRef]

20. Miyashita, N.T.; Mori, N.; Tsunewaki, K. Molecular variation in chloroplast DNA regions in ancestral species of wheat. Genetics 1994, 137, 883-889.

21. Jiang, J.; Gill, B.S. New 18S-26S ribosomal RNA gene loci: Chromosomal landmarks for the evolution of polyploid wheats. Chromosoma 1994, 103, 179-185. [CrossRef]

22. Badaeva, E.D.; Friebe, B.; Gill, B.S. Genome differentiation in Aegilops. 1. Distribution of highly repetitive DNA sequences on chromosomes of diploid species. Genome 1996, 39, 293-306. [CrossRef]

23. Sasanuma, T.; Miyashita, N.T.; Tsunewaki, K. Wheat phylogeny determined by RFLP analysis of nuclear DNA. 3. Intra- and interspecific variations of five Aegilops Sitopsis species. Theor. Appl. Genet. 1996, 92, 928-934. [CrossRef] [PubMed]

24. Upadhya, M.D.; Swaminathan, M.S. Genome analysis in Triticum zhukovskyi, a new hexaploid wheat. Chromosoma 1963, 14, 589-600. [CrossRef]

25. International Wheat Genome Sequencing Consortium. A chromosome-based draft sequence of the hexaploid bread wheat Triticum aestivum genome. Science 2014, 345, 1251788. [CrossRef] [PubMed]

26. International Wheat Genome Sequencing Consortium. Shifting the limits in wheat research and breeding using a fully annotated reference genome. Science 2018, 361. [CrossRef]

27. Avni, R.; Nave, M.; Barad, O.; Baruch, K.; Twardziok, S.O.; Gundlach, H.; Hale, I.; Mascher, M.; Spannagl, M.; Wiebe, K.; et al. Wild emmer genome architecture and diversity elucidate wheat evolution and domestication. Science 2017, 357, 93-97. [CrossRef] [PubMed]

28. Ling, H.Q.; Ma, B.; Shi, X.; Liu, H.; Dong, L.; Sun, H.; Cao, Y.; Gao, Q.; Zheng, S.; Li, Y.; et al. Genome sequence of the progenitor of wheat A subgenome Triticum urartu. Nature 2018, 557, 424-428. [CrossRef] [PubMed]

29. Zhao, G.; Zou, C.; Li, K.; Wang, K.; Li, T.; Gao, L.; Zhang, X.; Wang, H.; Yang, Z.; Liu, X.; et al. The Aegilops tauschii genome reveals multiple impacts of transposons. Nat. Plants 2017, 3, 946-955. [CrossRef]

30. Kihara, H. Cytologische und genetische studien bei wichtigen getreidearten mit besonderer rücksicht auf das verhalten der chromosomen und die sterilität in den bastarden. Mem. Coll. Sci. Kyoto Univ. 1924, 1, 1-200. 
31. Kihara, H. Genomanalyse bei Triticum und Aegilops. IX. Systematischer aufbau der gattung Aegilops auf genomanalytischer grundlage. Cytologia 1945, 14, 135-144. [CrossRef]

32. Lilienfeld, A.F.H. Kihara: Genome-analysis in Triticum and Aegilops. X. Concluding review. Cytologia 1951, 16, 101-123. [CrossRef]

33. Kihara, H.; Tanaka, M. Addendum to the classification of the genus Aegilops by means of genome-analysis. Wheat Inform. Serv. 1970, 30, 1-2.

34. Fedak, G. Alien Introgressions from wild Triticum species, T. monococcum, T. urartu, T. turgidum, T. dicoccum, T. dicoccoides, T. carthlicum, T. araraticum, T. timopheevii, and T. miguschovae. In Allien Introgression in Wheat. Cytogenetics, Molecular Biology, and Genomics; Molnár-Láng, M., Ceoloni, C., Doležel, J., Eds.; Springer: Berlin/Heidelberg, Germany, 2015; pp. 191-219.

35. Okamoto, M. Asynaptic effect of chromosome V. Wheat Info. Serv. 1957, 5, 6.

36. Sears, E.R.; Okamoto, M. Intergenomic chromosome relationship in hexaploid wheat. In Proceedings of the 10th International Congress of Genetics, Toronto, ON, Canada, 20-27 August 1958; pp. 258-259.

37. Riley, R.; Chapman, V. Genetic control of the cytologically diploid behaviour of hexaploid wheat. Nature 1958, 182, 713-715. [CrossRef]

38. Riley, R.; Chapman, V. The effect of the deficiency of the long arm of chromosome $5 \mathrm{~B}$ on meiotic pairing in Triticum aestivum. Wheat Info. Serv. 1964, 17, 12-15.

39. Riley, R.; Kempana, C. The homoeologous nature of the non-homologous meiotic pairing in Triticum aestivum deficient for chromosome V (5B). Heredity 1963, 18, 287-306. [CrossRef]

40. Zhang, P.; Dundas, I.S.; McIntosh, R.A.; Xu, S.S.; Park, R.F.; Gill, B.S.; Friebe, B. Wheat-Aegilops Introgressions. In Allien Introgression in Wheat. Cytogenetics, Molecular Biology, and Genomics; Molnár-Láng, M., Ceoloni, C., Doležel, J., Eds.; Springer: Berlin/Heidelberg, Germany, 2015; pp. 221-243. [CrossRef]

41. Sears, E.R. The Aneuploids of Common Wheat; Research Bulletin No. 572; University of Missouri: Columbia, MO, USA, 1954; pp. 1-58.

42. Sears, E.R. Nullisomic-tetrasomic combinations in hexaploid wheat. In Chromosome Manipulations and Plant Genetics; Riley, R., Lewis, K.R., Eds.; Springer: Berlin/Heidelberg, Germany, 1966; Volume 20, pp. $29-45$.

43. Okamoto, M. identification of the chromosomes of common wheat belonging to the A and B genomes. Can. J. Genet. Cytol. 1962, 4, 31-37. [CrossRef]

44. Naranjo, T.; Roca, A.; Goicoechea, P.G.; Giraldez, R. Chromosome Structure of Common Wheat: Genome Reassignment of Chromosomes $4 A$ and 4B; Miller, T.E., Koebner, R.M.D., Eds.; Cambridge: Cambridge, UK, 1988; pp. 115-120.

45. Shepherd, K.W.; Islam, A.K.M.R. Fourth Compendium of Wheat-Alien Chromosome lines; Miller, T.E., Koebner, R.M.D., Eds.; Cambridge: Cambridge, UK, 1988; pp. 1373-1398.

46. Naranjo, T.; Roca, A.; Goicoechea, P.G.; Giraldez, R. Arm homoeology of wheat and rye chromosomes. Genome 1987, 29, 873-882. [CrossRef]

47. Danilova, T.V.; Friebe, B.; Gill, B.S. Development of a wheat single gene FISH map for analyzing homoeologous relationship and chromosomal rearrangements within the Triticeae. Theor. Appl. Genet. 2014, 127, 715-730. [CrossRef] [PubMed]

48. Anderson, J.A.; Ogihara, Y.; Sorrells, M.E.; Tanskley, S.D. Development of a chromosomal arm map for wheat based on RFLP markers. Theor. Appl. Genet. 1992, 83, 1035-1043. [CrossRef]

49. Devos, K.M.; Dubcovsky, J.; Dvořák, J.; Chinoi, C.N.; Gale, M.D. Structural evolution of wheat chromosomes 4A, 5A, and 7B and its impact on recombination Theor. Appl. Genet. 1995, 91, 282-288. [CrossRef]

50. Dvorak, J.; Wang, L.; Zhu, T.T.; Jorgensen, C.M.; Deal, K.R.; Dai, X.T.; Dawson, M.W.; Müller, H.-G.; Luo, M.-C.; Ramasamy, R.K.; et al. Structural variation and rates of genome evolution in the grass family seen through comparison of sequences of genomes greatly differing in size. Plant J. 2018, 95, 487-503. [CrossRef] [PubMed]

51. Naranjo, T. Chromosome structure of durum wheat. Theor. Appl. Genet. 1990, 79, 397-400. [CrossRef] [PubMed]

52. Dvorak, J.; Wang, L.; Zhu, T.; Jorgensen, C.M.; Luo, M.-C.; Deal, K.R.; Gu, Y.Q.; Gill, B.S.; Distelfeld, A.; Devos, K.M.; et al. Reassessment of the evolution of wheat chromosomes 4A, 5A, and 7B. Theor. Appl. Genet. 2018, 131, 2451-2462. [CrossRef] [PubMed]

53. Gill, B.S.; Friebe, B.; Endo, T.R. Standard karyotype and nomenclature system for description of chromosome bands and structural aberrations in wheat (Triticum aestivum). Genome 1991, 34, 830-883. [CrossRef] 
54. Nelson, J.C.; Sorrells, M.E.; Van Deynze, A.E.; Lu, Y.H.; Atkinson, M.; Bernard, M.; Leroy, P.; Faris, J.D.; Anderson, J.A. Molecular mapping of wheat. Major genes and rearrangements in homoeologous groups 4, 5, and 7. Genetics 1995, 141, 721-731. [PubMed]

55. Endo, T.E.; Gill, B.S. The deletion stocks of common wheat. J. Hered. 1996, 87, 295-307. [CrossRef]

56. Mickelson-Young, L.; Endo, T.R.; Gill, B.S. A cytogenetic laddermap of the wheat homoeologous group-4 chromosomes. Theor. Appl. Genet. 1995, 90, 1007-1011. [CrossRef]

57. Miftahudin Ros, K.; Ma, X.-F.; Mahmoud, A.A.; Layton, J.; Rodriguez Milla, M.A.; Chikmawati, T.; Ramalingam, J.; Feril, O.; Pathan, M.S.; Surlan Momirovic, G.; et al. Analysis of expressed sequence tag loci on wheat chromosome group 4. Genetics 2004, 168, 651-663. [CrossRef]

58. Ma, J.; Stiller, J.; Wei, Y.; Zheng, Y.-L.; Devos, K.M.; Dolezel, J.; Liu, C. Extensive pericentric rearrangements in the bread wheat (Triticum aestivum L.) genotype 'Chinese Spring' revealed from chromosome shotgun data. Genome Biol. Evol. 2014, 6, 3039-3048. [CrossRef]

59. Jorgensen, C.; Luo, M.-C.; Ramasamy, R.; Dawson, M.; Gill, B.S.; Korol, A.B.; Distelfeld, A.; Dvorak, J. A high-density genetic map of wild emmer wheat from the Karaca dag region provides new evidence on the structure and evolution of wheat chromosomes. Front. Plant. Sci. 2017, 8, 1798. [CrossRef]

60. Salse, J.; Bolot, S.; Throude, M.; Jouffe, V.; Piegu, B.; Quraishi, U.M.; Calcagno, T.; Cooke, R.; Delseny, M.; Feuillet, C. Identification and characterization of shared duplications between rice and wheat provide new insight into grass genome evolution. Plant Cell 2008, 20, 11-24. [CrossRef] [PubMed]

61. Luo, M.C.; Deal, K.R.; Akhunov, E.D.; Akhunovaa, A.R.; Anderson, O.D.; Anderson, J.A.; Blake, N.; Clegg, M.T.; Coleman-Derr, D.; Conley, E.J.; et al. Genome comparisons reveal a dominant mechanism of chromosome number reduction in grasses and accelerated genome evolution in Triticeae. Proc. Natl. Acad. Sci. USA 2009, 106, 15780-15785. [CrossRef]

62. Jiang, J.; Gill, B.S. Different species-specific chromosome translocations in Triticum timopheevii and T. turgidum support the diphyletic origin of polyploid wheats. Chromosome Res. 1994, 2, 59-64. [CrossRef] [PubMed]

63. Maestra, B.; Naranjo, T. Structural chromosome differentiation between Triticum timopheevii and T. turgidum and T. aestivum. Theor Appl. Genet. 1999, 98, 744-750. [CrossRef]

64. Rodriguez, S.; Perera, E.; Maestra, B.; Diez, M.; Naranjo, T. Chromosome structure of Triticum timopheevii relative to T. turgidum. Genome 2000, 43, 923-930. [CrossRef] [PubMed]

65. Salina, E.A.; Leonova, I.N.; Efremova, T.T.; Röder, M.S. Wheat genome structure: Translocations during the course of polyploidization. Funct. Integr. Genomics 2006, 6, 71-80. [CrossRef] [PubMed]

66. Dobrovolskaya, O.; Boeuf, C.; Salse, J.; Pont, C.; Sourdille, P.; Bernard, M.; Salina, E. Microsatellite mapping of Ae. speltoides and map-based comparative analysis of the $\mathrm{S}, \mathrm{G}$, and $\mathrm{B}$ genomes of Triticeae species. Theor. Appl. Genet. 2011, 123, 1145-1157. [CrossRef]

67. Naranjo, T. Chromosome structure of Triticum longissimum relative to wheat. Theor. Appl. Genet. 1995, 91, 105-109. [CrossRef]

68. Naranjo, T.; Maestra, B. The effect of $p h$ mutations on homoeologous pairing in hybrids of wheat with Triticum longissimum. Theor. Appl. Genet. 1995, 91, 1265-1270. [CrossRef]

69. Maestra, B.; Naranjo, T. Homoeologous relationships of Triticum sharonense chromosomes to T. aestivum. Theor. Appl. Genet. 1997, 94, 657-663. [CrossRef]

70. Maestra, B.; Naranjo, T. Homoeologous relationships of Aegilops speltoides chromosomes to bread wheat. Theor. Appl. Genet. 1998, 97, 181-186. [CrossRef]

71. Zhang, H.; Reader, S.M.; Liu, X.; Jia, J.Z.; Gale, M.D.; Devos, K.M. Comparative genetic analysis of the Aegilops longissima and Ae. sharonensis genomes with common wheat. Theor. Appl. Genet. 2001, 103, 518-525. [CrossRef]

72. Olivera, P.D.; Kilian, A.; Wenzl, P.; Steffenson, B.J. Development of a genetic linkage map for Sharon goatgrass (Aegilops sharonensis) and mapping of a leaf rust resistance gene. Genome 2013, 56, 367-376. [CrossRef] [PubMed]

73. Yu, G.; Champouret, N.; Steuernagel, B.; Olivera, P.D.; Simmon, J.; William, C.; Johnson, R.; Moscou, M.J.; Hernandez-Pinzon, I.; Green, P.; et al. Discovery and characterization of two new stem rust resistance genes in Aegilops sharonensis. Theor. Appl. Genet. 2017, 130, 1207-1222. [CrossRef] [PubMed]

74. Luo, M.-C.; Deal, K.R.; Yang, Z.-L.; Dvorak, J. Comparative genetic maps reveal extreme crossover localization in the Aegilops speltoides chromosomes. Theor. Appl. Genet. 2005, 111, 1098-1106. [CrossRef] [PubMed] 
75. Zhang, H.; Jia, J.; Gale, M.D.; Devos, K.M. Relationships between the chromosomes of Aegilops umbellulata and wheat. Theor. Appl. Genet. 1998, 96, 69-75. [CrossRef]

76. Molnár, I.; Vrána, J.; Buresová, V.; Cápal, P.; Farkas, A.; Darkó, E.; Cseh, A.; Kubaláková, M.; Molnár-Láng, M.; Doležel, J. Dissecting the U, M, S and C genomes of wild relatives of bread wheat (Aegilops spp.) into chromosomes and exploring their synteny with wheat. Plant J. 2016, 88, 452-467. [CrossRef] [PubMed]

77. Danilova, T.V.; Akhunova, A.R.; Akhunov, E.D.; Friebe, B.; Gill, B.S. Major structural genomic alterations can be associated with hybrid speciation in Aegilops markgrafii (Triticeae). Plant J. 2017, 92, 317-330. [CrossRef]

78. Naranjo, T.; Fernández-Rueda, P. Homoeology of rye chromosome arms to wheat. Theor. Appl. Genet. 1991, 82, 577-586. [CrossRef]

79. Naranjo, T.; Fernández-Rueda, P. Pairing and recombination between individual chromosomes of wheat and rye in hybrids carrying the ph1b mutation. Theor. Appl. Genet. 1996, 93, 242-248. [CrossRef]

80. Devos, K.M.; Atkinson, M.D.; Chinoy, C.N.; Francis, H.A.; Harcourt, R.L.; Koebner, R.M.D.; Liu, C.J.; Masojć, P.; Xie, D.X.; Gale, M.D. Chromosomal rearrangements in the rye genome relative to that of wheat. Theor. Appl. Genet. 1993, 85, 673-680. [CrossRef] [PubMed]

81. Dubcovsky, J.; Luo, M.C.; Zhong, G.Y.; Bransteitter, R.; Desai, A.; Kilian, A.; Kleinhofs, A.; Dvorak, J. Genetic map of diploid wheat, Triticum monococcum L., and its comparison with maps of Hordeum vulgare L. Genetics 1996, 143, 983-999. [PubMed]

82. Hori, K.; Takehara, S.; Nankaku, N.; Sato, K.; Sasakuma, T.; Takeda, K. Barley EST markers enhance map saturation and QTL mapping in diploid wheat. Breeding Sci. 2007, 57, 39-45. [CrossRef]

83. Mayer, K.F.X.; Martis, M.; Hedley, P.E.; Šimková, H.; Liu, H.; Morris, J.A.; Steuernagel, B.; Taudien, S.; Roessner, S.; Gundlach, H.; et al. Unlocking the barley genome by chromosomal and comparative genomics. Plant Cell 2011, 23, 1249-1263. [CrossRef] [PubMed]

84. Mascher, M.; Gundlach, H.; Himmelbach, A.; Beier, S.; Twardziok, S.O.; Wicker, T.; Radchuk, V.; Dockter, C.; Hedley, P.E.; Russell, J.; et al. A chromosome conformation capture ordered sequence of the barley genome. Nature 2017, 544, 427-433. [CrossRef] [PubMed]

85. Said, M.; Hřibová, E.; Danilova, T.V.; Karafiátová, M.; Čížková, J.; Friebe, B.; Doležel, J.; Gill, B.S.; Vrána, J. The Agropyron cristatum karyotype, chromosome structure and cross-genome homoeology as revealed by fluorescence in situ hybridization with tandem repeats and wheat single-gene probes. Theor. Appl. Genet. 2018, 131, 2213-2227. [CrossRef] [PubMed]

86. Larson, S.R.; Kishii, M.; Tsujimoto, H.; Qi, L.; Chen, P.; Lazo, G.R.; Jensen, K.B.; Wang, R.R.C. Leymus EST linkage maps identify $4 \mathrm{NsL}-5 \mathrm{NsL}$ reciprocal translocation, wheat-Leymus chromosome introgressions, and functionally important gene loci. Theor. Appl. Genet. 2012, 124, 189-206. [CrossRef]

87. Grewal, S.; Yang, C.; Hubbart Edwards, S.; Scholefeld, D.; Ashling, S.; Burridge, A.J.; King, I.P.; King, J. Characterisation of Thinopyrum bessarabicum chromosomes through genome-wide introgressions into wheat. Theor. Appl. Genet. 2018, 131, 389-406. [CrossRef]

88. Wang, R.R.C.; Larson, S.R.; Jensen, K.B.; Bushman, B.S.; DeHaan, L.R.; Wang, S.; Yan, X. Genome evolution of intermediate wheatgrass as revealed by EST-SSR markers developed from its three progenitor diploid species. Genome 2015, 58, 63-70. [CrossRef]

89. Kantarski, T.; Larson, S.; Zhang, X.; DeHaan, L.; Borevitz, J.; Anderson, J.; Poland, J. Development of the first consensus genetic map of intermediate wheatgrass (Thinopyrum intermedium) using genotyping-by-sequencing. Theor. Appl. Genet. 2017, 130, 137-150. [CrossRef]

90. Naranjo, T. The use of homoeologous pairing in the identification of homoeologous relationships in Triticeae. Hereditas 1992, 116, 219-223. [CrossRef]

91. Li, W.; Challa, G.S.; Zhu, H.; Wei, W. Recurrence of chromosome rearrangements and reuse of DNA breakpoints in the evolution of the Triticeae genomes. G3 2016, 6, 3837-3847. [CrossRef] [PubMed]

92. Feldman, M.; Levy, A.A. Genome evolution due to allopolyploidization in wheat. Genetics 2012, 192, $763-774$. [CrossRef] [PubMed]

93. Leitch, I.J.; Bennnett, M.D. Polyploidy in Angiosperms. Trends Plant Sci. 1997, 2, 470-476. [CrossRef]

94. Keeney, S.; Giroux, C.N.; Kleckner, N. Meiosis-specific DNA double- strand breaks are catalyzed by Spo11, a member of a widely conserved protein family. Cell 1997, 88, 375-384. [CrossRef]

95. Robert, T.; Vrielynck, N.; Mézard, C.; de Massy, B.; Grelon, M. A new light on the meiotic DSB catalytic complex. Semin. Cell Dev. Biol. 2016, 54, 165-176. [CrossRef] [PubMed] 
96. Pradillo, M.; Santos, J.L. The template choice decision in meiosis: Is the sister important? Chromosoma 2011, 120, 447-454. [CrossRef] [PubMed]

97. Hunter, N.; Kleckner, N. The single-end invasion: An asymmetric intermediate at the double-strand break to double-holliday junction transition of meiotic recombination. Cell 2001, 106, 59-70. [CrossRef]

98. Mercier, R.; Mézard, C.; Jenczewski, E.; Macaisne, N.; Grelon, M. The molecular biology of meiosis in plants. Annu. Rev. Plant Biol. 2015, 66, 297-327. [CrossRef]

99. Lambing, C.; Franklin, F.C.H.; Wang, C.-J.R. Understanding and manipulating meiotic recombination in plants. Plant Physiol. 2017, 173, 1530-1542. [CrossRef]

100. Lambing, C.; Heckmann, S. Tackling plant meiosis: From model research to crop improvement. Front. Plant Sci. 2018, 9, 829. [CrossRef] [PubMed]

101. Kohl, K.P.; Sekelsky, J. Meiotic and mitotic recombination in meiosis. Genetics 2013, 194, 327-334. [CrossRef] [PubMed]

102. Fernandes, J.B.; Seguéla-Arnaud, M.; Larchevêque, C.; Lloyd, A.H.; Mercier, R. Unleashing meiotic crossovers in hybrid plants. Proc. Natl. Acad. Sci. USA 2018, 15, 2431-2436. [CrossRef] [PubMed]

103. Bolaños-Villegas, P.; De, K.; Pradillo, M.; Liu, D.; Makaroff, C.A. In favor of establishment: Regulation of chromatid cohesion in plants. Front. Plant Sci. 2017, 8, 846. [CrossRef] [PubMed]

104. Li, X.; Dawe, R.K. Fused sister kinetochores initiate the reductional division in meiosis I. Nature Cell Biol. 2009, 11, 1103-1108. [CrossRef]

105. Mézard, C.; Tagliaro Jahns, M.; Grelon, M. Where to cross? New insights into the location of meiotic crossovers. Trends Genet. 2015, 31, 393-401. [CrossRef] [PubMed]

106. Blary, A.; Jenczewski, E. Manipulation of crossover frequency and distribution for plant breeding. Theor. Appl. Genet. 2019, 132, 575-592. [CrossRef]

107. Choi, K.; Zhao, X.; Tock, A.J.; Lambing, C.; Underwood, C.J.; Hardcastle, T.J.; Serra, H.; Kim, J.; Cho, H.S.; Kim, J.; et al. Nucleosomes and DNA methylation shape meiotic DSB frequency in Arabidopsis thaliana transposons and gene regulatory regions. Genome Res. 2018, 1, 1-15. [CrossRef]

108. He, Y.; Wang, M.; Dukowic-Schulze, S.; Zhou, A.; Tiang, C.-L.; Shilo, S.; Sidhu, G.K.; Eichten, S.; Bradbury, P.; Springer, N.M.; et al. Genomic features shaping the landscape of meiotic double-strand-break hotspots in maize. Proc. Natl. Acad. Sci. USA 2017, 114, 12231-12236. [CrossRef]

109. Anderson, L.K.; Doyle, G.G.; Brigham, B.; Carter, J.; Hooker, K.D.; Lai, A.; Rice, M.; Stack, S.M. High-resolution crossover maps for each bivalent of Zea mays using recombination nodules. Genetics 2003, 165, 849-865.

110. Lukaszewski, A.J.; Curtis, C.A. Physical distribution of recombination in B-genome chromosomes of tetraploid wheat. Theor. Appl. Genet. 1993, 86, 121-127. [CrossRef] [PubMed]

111. Akhunov, E.D.; Goodyear, A.W.; Geng, S.; Qi, L.L.; Echalier, B.; Gill, B.S.; Miftahudin, J.; Gustafson, J.P.; Lazo, G.; Chao, S.; et al. The organization and rate of evolution of wheat genomes are correlated with recombination rates along chromosome arms. Genome Res. 2003, 13, 753-763. [CrossRef] [PubMed]

112. Choulet, F.; Alberti, A.; Theil, S.; Glover, N.; Barbe, V.; Daron, J.; Pingault, L.; Sourdille, P.; Couloux, A.; Paux, E.; et al. Structural and functional partitioning of bread wheat chromosome 3B. Science 2014, 345, 1249721. [CrossRef] [PubMed]

113. Higgins, J.D.; Perry, R.M.; Barakate, A.; Ramsay, L.; Waugh, R.; Halpin, C.; Armstrong, S.J.; Franklin, F.C.H. Spatiotemporal asymmetry of the meiotic program underlies the predominantly distal distribution of meiotic crossovers in barley. Plant Cell 2012, 24, 4096-4109. [CrossRef] [PubMed]

114. Albini, S.M.; Jones, G.H. Synaptonemal complex spreading in Allium cepa and A. fistulosum: I. The initiation and sequence of pairing. Chromosoma 1987, 95, 324-338. [CrossRef]

115. Choi, K.; Zhao, X.; Kelly, K.A.; Venn, O.; Higgins, J.D.; Yelina, N.E.; Hardcastle, T.J.; Ziolkowski, P.A.; Copenhaver, G.P.; Franklin, F.C.; et al. Arabidopsis meiotic crossover hot spots overlap with H2A.Z nucleosomes at gene promoters. Nat. Genet. 2013, 45, 1327-1336. [CrossRef] [PubMed]

116. Yelina, N.E.; Lambing, C.; Hardcastle, T.J.; Zhao, X.; Santos, B.; Henderson, I.R. DNA methylation epigenetically silences crossover hot spots and controls chromosomal domains of meiotic recombination in Arabidopsis. Genes Dev. 2015, 29, 2183-2202. [CrossRef] [PubMed]

117. Underwood, C.J.; Choi, K.; Lambing, C.; Zhao, X.; Serra, H.; Borges, F.; Simorowski, J.; Ernst, E.; Jacob, Y.; Henderson, I.R.; et al. Epigenetic activation of meiotic recombination near Arabidopsis thaliana centromeres via loss of H3K9me2 and non-CG DNA methylation. Genome Res. 2018, 28, 1-13. [CrossRef] 
118. Griffiths, S.; Sharp, R.; Foot, T.N.; Bertin, I.; Wanous, M.; Reader, S.; Colas, I.; Moore, G. Molecular characterization of $P h 1$ as a major chromosome pairing locus in polyploid wheat. Nature 2006, 439, 749-752. [CrossRef]

119. Bhullar, R.; Nagarajan, R.; Bennypaul, H.; Sidhu, G.K.; Sidhu, G.; Rustgi, S.; von Wettstein, D.; Gill, K.S. Silencing of a metaphase I specific gene present in the $P h 1$ locus results in phenotype similar to that of the Ph1 mutations. Proc. Nat. Acad. Sci. USA 2014, 111, 14187-14192. [CrossRef]

120. Rey, M.D.; Martín, A.M.; Higgins, J.; Swarbreck, D.; Uauy, C.; Shaw, P.; Moore, G. Exploiting the ZIP4 homologue within the wheat $P h 1$ locus has identified two lines exhibiting homoeologous crossover in wheat-wild relative hybrids. Mol. Breed. 2017, 37, 95. [CrossRef]

121. Rey, M.-D.; Martín, A.C.; Smedley, M.; Hayta, S.; Harwood, W.; Shaw, P.; Moore, G. Magnesium increases homoeologous crossover frequency during meiosis in ZIP4 (Ph1 gene) mutant wheat-wild relative hybrids. Front. Plant Sci. 2018, 9, 509. [CrossRef] [PubMed]

122. Martín, A.C.; Borrill, P.; Higgins, J.; Alabdullah, A.; Ramírez-González, R.H.; Swarbreck, D.; Uauy, C.; Shaw, P.; Moore, G. Genome-wide transcriprion during early wheat meiosis is indepencent of synapsis, ploidy level and the Ph1 locus. Front. Plant Sci. 2018, 9, 1791. [CrossRef]

123. Mello-Sampayo, T. Genetic regulation of meiotic chromosome pairing by chromosome 3D of Triticum aestivum. Nat. New Biol. 1971, 230, 22-23. [CrossRef] [PubMed]

124. Naranjo, T.; Benavente, A. The mode and regulation of chromosome pairing in wheat-alien hybrids (Ph genes, an updated view). In Allien Introgression in Wheat. Cytogenetics, Molecular Biology, and Genomics; Molnár-Láng, M., Ceoloni, C., Doležel, J., Eds.; Springer: Berlin/Heidelberg, Germany, 2015; pp. 133-162. [CrossRef]

125. Krasilevaa, K.V.; Vasquez-Gross, H.A.; Howell, T.; Bailey, P.; Paraiso, F.; Clissold, L.; Simmonds, J.; Ramirez-Gonzalez, R.H.; Wang, X.; Borrill, P.; et al. Uncovering hiden variation in polyploid wheat. Pro. Nat. Acad. Sci. USA 2017, 114, 913-921. [CrossRef]

126. Fuchs, L.K.; Jenkins, G.; Phillips, D.W. Anthropogenic impacts on meiosis in plants. Front. Plant Sci. 2018, 9, 1429. [CrossRef] [PubMed]

127. Lloyd, A.; Morgan, C.; Franklin, C.; Bomblies, K. Plasticity of meiotic recombination rates in response to temperature in Arabidopsis. Genetics 2018, 208, 1409-1420. [CrossRef] [PubMed]

128. Phillips, D.; Jenkins, G.; Macaulay, M.; Nibau, C.; Wnetrzak, J.; Fallding, D.; Colas, I.; Oakey, H.; Waugh, R.; Ramsay, L. The effect of temperature on the male and female recombination landscape of barley. New Phytol. 2015, 208, 421-429. [CrossRef]

129. Bennett, M.D.; Rees, H. Induced variation in chiasma frequency in rye in response to phosphate treatments. Genet. Res. 1970, 16, 325-331. [CrossRef]

130. Börner, A.; Ogbonnaya, F.C.; Röder, M.S.; Rasheed, A.; Peryannan, S.; Lagudah, E.S. Aegilops tauschii introgresions in wheat. In Alien Introgression in Wheat. Cytogenetics, Molecular Biology, and Genomics; Molnár-Láng, M., Ceoloni, C., Doležel, J., Eds.; Springer: Berlin/Heidelberg, Germany, 2015; pp. $245-271$. [CrossRef]

131. Sears, E.R. An induced mutant with homoeologous pairing in wheat. Can. J. Genet. Cytol. 1977, 19, 585-593. [CrossRef]

132. Sánchez-Morán, E.; Benavente, E.; Orellana, J. Analysis of karyotypic stability of homoeologous-pairing (ph) mutants in allopolyploid wheats. Chromosoma 2001, 110, 371-377. [CrossRef]

133. Li, H.; Deal, K.R.; Luo, M.-C.; Ji, W.; Distelfeld, A.; Dvorak, J. Introgression of the Aegilops speltoides Su1-Ph1 suppressor into wheat. Front. Plant Sci. 2017, 8, 2163. [CrossRef]

134. Riley, R.; Chapman, V.; Johnson, R. Introduction of yellow rust resistance of Aegilops comosa into wheat by genetically induced homoeologous recombination. Nature 1968, 217, 383-384. [CrossRef]

135. Riley, R.; Chapman, V.; Johnson, R. The incorporation of alien disease resistance in wheat by genetic interference with the regulation of meiotic chromosome synapsis. Genet. Res. 1968, 12, 199-219. [CrossRef]

136. Sears, E.R. Agropyron-Wheat Transfer Induced by Homoeologous Pairing; Sears, E.R., Sears, L.M.S., Eds.; Agriculture Experiment Station: Arlington, VI, USA, 1973; pp. 191-199.

137. Ceoloni, C.; Kuzmanovic, L.; Forte, P.; Virili, M.E.; Bitti, A. Wheat-perennial Triticeae introgressions: Major achievements and prospects. In Alien Introgression in Wheat. Cytogenetics, Molecular Biology, and Genomics; Molnár-Láng, M., Ceoloni, C., Doležel, J., Eds.; Springer: Berlin/Heidelberg, Germany, 2015; pp. $273-313$. [CrossRef] 
138. Lukaszewski, A. Introgressions between wheat and rye. In Alien Introgression in Wheat. Cytogenetics, Molecular Biology, and Genomics; Molnár-Láng, M., Ceoloni, C., Doležel, J., Eds.; Springer: Berlin/Heidelberg, Germany, 2015; pp. 163-189. [CrossRef]

139. Molnár-Láng, M.; Linc, G. Wheat-barley hybrids and introgession lines. In Alien Introgression in Wheat. Cytogenetics, Molecular Biology, and Genomics; Molnár-Láng, M., Ceoloni, C., Doležel, J., Eds.; Springer: Berlin/Heidelberg, Germany, 2015; pp. 315-345. [CrossRef]

140. Martín, A.; Sánchez-Monge Laguna, E. A hybrid between Hordeum chilense and Triticum turgidum. Cereal Res. Commun. 1980, 8, 349-353.

141. Martín, A.; Sánchez-Monge Laguna, E. Cytology and morphology of the amphiploid Hordeum chilense $\mathrm{x}$ Triticum turgidum conv. Durum. Euphytica 1982, 31, 261-267. [CrossRef]

142. Rey, M.D.; Calderón, M.C.; Prieto, P. The use of the $p h 1 b$ mutant to induce recombination between the chromosomes of wheat and barley. Front. Plant Sci. 2015, 6, 160. [CrossRef]

143. Sears, E.R. Transfer of alien genetic material to wheat. In Wheat Science-Today and Tomorrow; Evans, L., Peacock, W.J., Eds.; Cambridge University Press: Cambridge, UK, 1981; pp. 75-89.

144. Lukaszewski, A.J. Manipulation of homologous and homoeologous chromosome recombination in wheat. In Plant Cytogenetics. Methods in Molecular Biology; Kianian, S., Kianian, P., Eds.; Springer: Berlin/Heidelberg, Germany, 2016; pp. 77-89. [CrossRef]

145. Sallee, P.J.; Kimber, G. An Analysis of the Pairing of Wheat Telocentric Chromosomes; Ramanujan, S., Ed.; Springer: New Dehli, India, 1978; pp. 408-419.

146. Holm, P.B. Chromosome pairing and chiasma formation in allohexaploid wheat: Triticum aestivum analyzed by spreading of meiotic nuclei. Carlsberg Res. Commun. 1986, 51, 239-294. [CrossRef]

147. Ederveen, A.; Lai, Y.; van Driel, M.A.; Gerats, T.; Peters, J.L. Modulating crossover positioning by introducing large structural changes in chromosomes. BMC Genomics 2015, 16, 89. [CrossRef]

148. Curtis, C.A.; Lukaszewski, A.J.; Chrzastek, M. Metaphase-I pairing of deficient chromosomes and genetic mapping of deficiency breakpoints in wheat. Genome 1991, 34, 553-560. [CrossRef]

149. Jones, L.E.; Rybka, K.; Lukaszewski, A.J. The effect of a deficiency and a deletion on recombination in chromosome 1BL in wheat. Theor. Appl. Genet. 2002, 104, 1204-1208. [CrossRef]

150. Qi, L.L.; Friebe, B.; Gill, B.S. A strategy for enhancing recombination in proximal regions of chromosomes. Chromosome Res. 2002, 10, 645-654. [CrossRef]

151. Naranjo, T.; Valenzuela, N.T.; Perera, E. Chiasma frequency is region-specific and chromosome conformation-dependent in a rye chromosome added to wheat. Cytogenet. Genome Res. 2010, 129, 133-142. [CrossRef]

152. Lukaszewski, A.J. Unexpected behaviour of an inverted rye chromosome arm in wheat. Chromosoma 2008, 117, 569-578. [CrossRef]

153. Lukaszewski, A.J.; Kopecky, D.; Linc, G. Inversions of chromosome arms 4AL and 2BS in wheat invert the patterns of chiasma distribution. Chromosoma 2012, 121, 201-208. [CrossRef]

154. Valenzuela, N.T.; Perera, E.; Naranjo, T. Dynamics of rye chromosome 1R regions with high and low crossover frequency in homology search and synapsis development. PLoS ONE 2012, 7, e36385. [CrossRef]

155. Naranjo, T. Forcing the shift of the crossover site to proximal regions in wheat chromosomes. Theor. Appl. Genet. 2015, 128, 1855-1863. [CrossRef]

156. Sears, E.R. Mutations in Wheat That Raise the Level of Meiotic Chromosome Pairing; Gustafson, J.P., Ed.; Plenum Press: New York, NY, USA, 1984; pp. 295-300.

157. Naranjo, T.; Fernández-Rueda, P.; Goicoechea, P.G.; Roca, A.; Giráldez, R. Homoeologous pairing and recombination between the long arms of group 1 chromosomes in wheat $x$ rye hybrids. Genome 1988, 32, 293-301. [CrossRef]

(C) 2019 by the author. Licensee MDPI, Basel, Switzerland. This article is an open access article distributed under the terms and conditions of the Creative Commons Attribution (CC BY) license (http://creativecommons.org/licenses/by/4.0/). 